\title{
An Assessment of Passive Microwave and Millimeterwave Sensors for the Standoff Detection of Chemical Agents
}

Gerald T. Fraser

Angela R. Hight Walker 


\title{
An Assessment of Passive Microwave and Millimeterwave Sensors for the Standoff Detection of Chemical Agents
}

\author{
Gerald T. Fraser \\ Angela R. Hight Walker \\ Optical Technology Division \\ Physics Laboratory \\ National Institute of Standards and Technology \\ Gaithersburg, MD 20899-8441
}

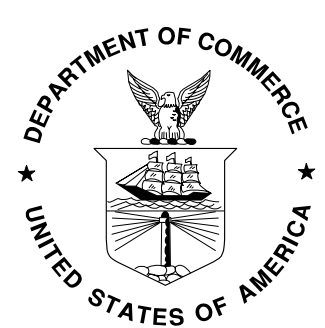

U.S. DEPARTMENT OF COMMERCE

Donald L. Evans, Secretary

TECHNOLOGY ADMINISTRATION

Phillip J. Bond, Under Secretary of Commerce for Technology NATIONAL INSTITUTE OF STANDARDS AND TECHNOLOGY Arden L. Bement, Jr., Director 


\title{
An Assessment of Passive Microwave and Millimeterwave Sensors for the Standoff Detection of Chemical Agents
}

\author{
Gerald T. Fraser and Angela R. Hight Walker \\ Optical Technology Division \\ National Institute of Standards and Technology \\ Gaithersburg, MD 20899-8441
}

\begin{abstract}
A radiative-transfer model is used to assess the potential of ground-based, upwardlooking, passive microwave and millimeterwave radiometry from $5 \mathrm{GHz}$ to $300 \mathrm{GHz}$ for the standoff detection of chemical agents. The microwave and millimeterwave spectra of the agents and simulants were modeled using published ab initio quantum-mechanical predictions of the spectroscopic constants validated by laboratory spectroscopic measurements. The pressure-broadened microwave-to-millimeterwave rotational band contours vary in intensity, shape, and peak frequency with agent or simulant, providing the potential for both identification and quantification. The radiative-transfer calculations show that the detection sensitivity is greatest for zenith angles near vertical $\left(\theta_{\text {zenith }} \approx 0^{\circ}\right)$, with changes in brightness temperature upon introduction of a $1 \mathrm{~km}$ thick, $1 \mu \mathrm{mol} / \mathrm{mol}$ concentration chemical agent cloud of a much as $12 \mathrm{~K}$ for soman for a water-vapor column of $1 \mathrm{~cm}$ (relative humidity $\approx 38 \%$ ). The detection sensitivity as measured by the magnitude of the change in brightness temperature decreases with increasing water-vapor column and with increasing zenith angle till it effectively vanishes at horizontal viewing angles $\left(\theta_{\text {zenith }} \approx 90^{\circ}\right)$. The analysis determines that the performance of a realistic sensor will be limited by the atmosphere opacity near horizontal viewing angles of greatest interest for standoff detection and by background brightness temperature fluctuations due to water-column variations driven by atmospheric turbulence of short and long-term duration. It is concluded that ground-based, passive, microwave and millimeterwave radiometry is not a viable technology for the sensitive standoff detection and identification of chemical agents.
\end{abstract}

\section{INTRODUCTION}

Optical sensors are widely employed in the detection of chemical-warfare agents, precursors, and decomposition products for application to troop protection, intelligence gathering, treaty monitoring, and homeland security. Such sensors are essential for providing evidence of the development, manufacture, deployment, testing, or use of chemical agents by military adversaries and terrorist groups. Present optical sensors suffer from high false-alarm rates, low sensitivity, high maintenance and acquisition costs, slow response time, and poor specificity. The unsatisfactory performance of these sensors has led to the simultaneous deployment of several different types of sensors in real applications to improve overall detection system sensitivity and accuracy. Moreover, a significant national research and development effort is being devoted to the improvement of sensors for chemical-agent detection. Many of these sensors also have 
application to the detection of biological agents, and such dual-application sensors are attracting wide interest.

Both point and standoff detection systems for chemical agents have been developed and deployed, often in complimentary roles, as part of a complete detection system for troop and civilian protection. Standoff systems provide early warning of an attack, usually through the detection and identification of a distant chemical-agent cloud or release, and require exceptional performance to ensure that the correct response is rapidly implemented by the personnel being protected. The warning delivered by a standoff detection system is typically verified by a point detection system deployed at the perimeter of a site. Because of its close proximity to the personnel being protected, an effective point detection system must have sensitivities significantly greater than the median incapacitating dose of an agent, approximately $25 \mathrm{mg} \mathrm{min} / \mathrm{m}^{3}$ for sarin by inhalation, i.e. $25 \mathrm{mg} / \mathrm{m}^{3}$ for a $1 \mathrm{~min}$ exposure [1].

In the present report we assess the potential of passive microwave to millimeterwave sensors for the standoff detection of chemical-warfare agents, precursors, and decomposition products. Here, we take the microwave and millimeterwave spectral region to extend from approximately $5 \mathrm{GHz}$ to $300 \mathrm{GHz}$. This spectral window is characterized by good atmospheric transparency and relatively mature technology. At higher frequencies, near $1 \mathrm{THz}$, the atmospheric transmission decreases significantly due to water-vapor absorption, as shown in Figure 1 below.

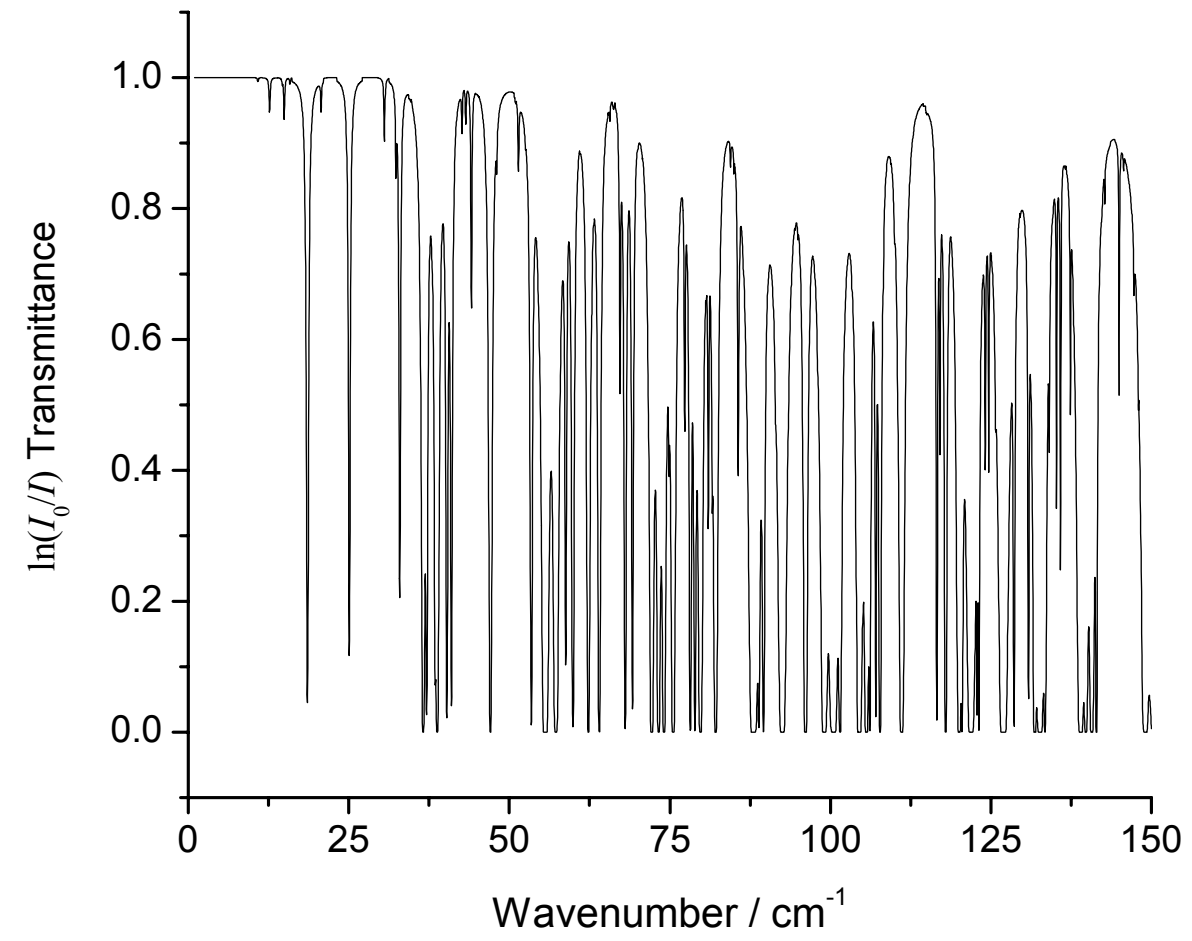

Figure 1. Absorption spectrum of water vapor in the atmosphere for a $1 \mathrm{~m}$ optical pathlength. The water-vapor partial pressure is $0.79 \mathrm{kPa}$ [5.9 Torr], which corresponds to a relative humidity of approximately $45 \%$ at $288.15 \mathrm{~K}$. [11] 
The tremendous success of infrared techniques for the detection of chemical agents, as demonstrated by the availability of several deployed military systems using this technology, motivates the detailed examination of the microwave and millimeterwave spectral region presented in this report. For reconnaissance, surveillance, and targeting, microwave and millimeterwave sensors offer potential advantages over infrared sensors under conditions of poor visibility, such as when clouds, fog, haze, dust, or smoke are present or rain or snow is falling, common occurrences on the battlefield. This advantage arises from the general lower scattering and absorption by particulates of long wavelength radiation.

In the infrared, both passive and active standoff detection systems have been demonstrated and fielded. Passive infrared sensors generally use thermal imaging within atmospheric transmission windows to detect small changes in the thermal background due to the presence of a chemical-agent cloud. Such sensors range from relatively unsophisticated filter radiometers to highly sophisticated hyperspectral imaging system based on interferometry. Examples of passive infrared sensors include the U.S. Military's M21 and JSLSCAD (Joint Service Lightweight Standoff Chemical Agent Detector) chemical-agent detectors, both based on a Michelson interferometer operating in the infrared fingerprint region between approximately $800 \mathrm{~cm}^{-1}$ and $1200 \mathrm{~cm}^{-1}$. The published optical-pathlength-times-concentration $(C L)$ detection sensitivity for the JSLCAD of $135 \mathrm{mg} / \mathrm{m}^{2}$ for a nerve agent [2] corresponds to approximately $23 \mathrm{ppb}$ of sarin (GB) in a $1 \mathrm{~km}$ long cloud along the line of sight, a concentration level which would require approximately 3 hours of continuous exposure to incapacitate $50 \%$ of the exposed personnel.

Active infrared sensors typically use infrared lidar to detect the approach of a chemical cloud. The backscattered radiation from one or more pulsed lasers is collected and analyzed providing information on the composition and range of the cloud. The planned Artemis active standoff chemical-agent detection system is one example of an infrared lidar sensor, providing new alternatives to passive infrared systems. The expected range of the Artemis system of approximately $20 \mathrm{~km}$ is four times greater than the $5 \mathrm{~km}$ range of the M21 and JSLSCAD passive infrared systems. The anticipated sensitivity for a nerve agent of $10 \mathrm{mg} / \mathrm{m}^{2}$ [3], or $2 \mathrm{ppb}$ ( $\left.2 \mathrm{nmole} / \mathrm{mole}\right)$ for a $1 \mathrm{~km}$ long cloud probed by the laser, is approximately an order-of-magnitude improvement over thermal imaging.

In contrast to the infrared, the application of microwave and millimeterwave technology to chemical agent sensing is still in its infancy. Several studies have explored the potential to use microwave and millimeterwave spectroscopy for chemical-agent detection. These studies looked at point detection systems based on Stark-modulation microwave spectroscopy [4] and pulsed-molecular-beam Fourier-transform microwave spectroscopy [5-7], as well as standoff detection systems [8-10].

The study of McIlwain, Smith, and Finnegan [9] is particularly relevant for the present investigation as they examined the application of microwave absorption spectroscopy up to $100 \mathrm{GHz}$ for the active stand-off detection of chemical agents. McIlwain et al. [9] determined detection sensitivities on the order of $10 \mu \mathrm{mol} / \mathrm{mol}(10 \mathrm{ppm})$, which led to the 
recommendation that "an experimental program be undertaken to accurately characterize the microwave spectral contours and intensity profiles of chemical agent and simulant molecules. The design and construction of prototype wide area and point microwave rotational absorption (MRA) reconnaissance devices are also recommended." The present study expands on the work of McIlwain et al. [9] by extending the spectral window examined to $300 \mathrm{GHz}$, near the peak of the intensity of the pure rotational bands of chemical agents at room temperature, and by exploring the potential of passive microwave and millimeterwave sensing. The recommendations of McIlwain et al., together with the significant advances in millimeterwave technology and in our knowledge of the rotational bands of chemical agents, provide significant motivation to determine whether the present successes in the infrared sensing of chemical agents can be extended to the longer-wavelength microwave and millimeterwave regimes.

In assessing the potential of microwave and millimeterwave radiometry and spectroscopy to detect, identify, and quantify chemical agents we develop below a model for a passive sensor operating in this wavelength region. Passive methods offer an advantage over active sensors in that no signal is emitted by the sensor, allowing the user to more easily avoid detection. The general sensor approach in the microwave and millimeterwave region is similar to that used in the infrared, except instead of using vibrational band positions and intensities for agent identification and quantification, rotational band intensities and profiles are used.

For in-situ measurements of chemical agents in the ambient air, the microwave to millimeterwave spectral regions are at a significant disadvantage relative to the infrared spectral region. Atmospheric-pressure-broadened microwave and millimeterwave spectra have significantly lower information content than the corresponding infrared spectra, restricting the ability of standoff microwave and millimeterwave methods to positively identify a specific chemical agent and accurately determine its concentration. Dopplerlimited absorption spectra in the microwave to millimeterwave region and in the infrared region, such as might be obtained in the laboratory, provide sufficient information to unambiguously identify and quantify a chemical agent. To record such Doppler-limited spectra requires sophisticated instrumentation able to deliver high-spectral resolution and sensitivity at sample pressures near $1 \mathrm{~Pa}[7.5 \mathrm{mTorr}]$ in the microwave to millimeterwave region and near $1 \mathrm{kPa}$ [7.5 Torr] in the infrared necessary to achieve Doppler-limited linewidths. At these low sample pressures, sensitivity will often be insufficient to obtain spectra of sufficient intensity for speciation and quantification, even with prior sample preparation to increase the concentration of the agent.

In Figure 2 we show model atmospheric-pressure microwave to submillimeterwave spectra for the two nerve agents, sarin (GB) and soman (GD), and the nerve-agent simulant, dimethyl methylphosphonate (DMMP). The spectra were calculated assuming an atmosphere of air with an agent or simulant concentration of $1 \mathrm{ppm}(1 \mu \mathrm{mole} / \mathrm{mole})$ and an optical pathlength of $100 \mathrm{~m} \mathrm{[11]}$. The spectral simulations use ab initio quantumchemistry calculations of the rotational spectroscopic constants and electric dipole moments $[6,7,12]$. The rotational constants and electric dipole moments for thermally populated vibrationally excited states and conformational isomers were assumed to be 
unchanged from the ground-state values. Values for the rotational constants, electric dipole moments, and the temperature-dependent partition function were used as input to the spectral prediction program of Pickett [13] to produce a list of absorption lines and their integrated intensities for the spectral modeling. The two approximations, that the spectroscopic constants are well predicted by quantum chemistry calculations and that their variation between conformations and vibrational states can be ignored, have a negligible effect on the present modeling and associated conclusions since individual rotational lines are not being measured. It should be noted that good agreement is obtained in comparisons between experimentally measured and ab initio calculated spectroscopic constants for agents and simulants such as DMMP, sarin, and soman.

The overall microwave to submillimeterwave band profile as a function of frequency, $v$, is the sum of the profiles from thousands of individual lines $(288,662$ in the case of sarin with the imposition of a reasonable intensity cutoff) at frequencies, $v_{i}$, each characterized by a van Vleck-Weisskopf lineshape function,

$S_{v V W}\left(v, v_{i}\right)=\frac{1}{\pi}\left(\frac{v}{v_{i}}\right)\left[\frac{\gamma}{\left(v-v_{i}\right)^{2}+\gamma^{2}}+\frac{\gamma}{\left(v+v_{i}\right)^{2}+\gamma^{2}}\right]$,

with an assumed air pressure-broadened half-width-at-half-maximum (HWHM) linewidth of $\gamma=3.8 \mathrm{GHz}$ at a total pressure of $101.325 \mathrm{kPa}[1 \mathrm{~atm}, 760$ Torr, or 1013.25 millibar], i.e. $37 \mathrm{MHz} / \mathrm{kPa}$ [5 MHz/Torr]. Unlike the Lorentzian lineshape function widely used in the infrared, the van Vleck-Weisskopf lineshape function goes to zero at zero-frequency. The continuum appearance of the band profiles is the consequence of imposing a broad lineshape profile $(\mathrm{HWHM}=3.8 \mathrm{GHz})$ upon the many thousands of individual rotational transitions contributing to the spectrum.

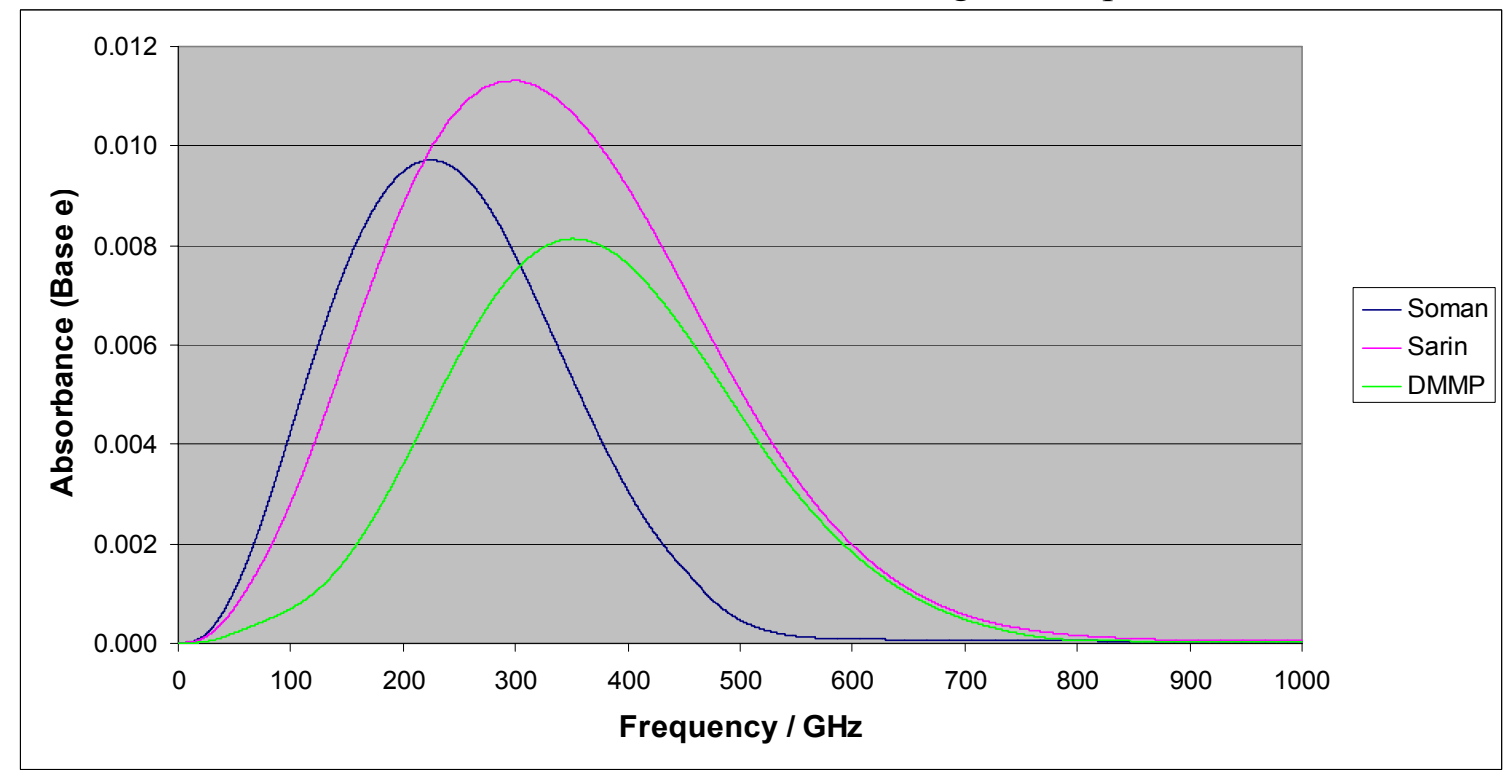

Figure 2. Simulated absorbance spectra for the chemical agents soman and sarin and the simulant dimethyl methyl phosphonate (DMMP) at a concentration of $1 \mu \mathrm{mol} / \mathrm{mol}[1 \mathrm{ppm}]$ and a pathlength of $100 \mathrm{~m}$. 
The microwave-to-millimeterwave spectra of Figure 2 can be compared with the infrared spectra of these agents and simulants shown in Figure 3 [14-16]. In the infrared, a series of peaks are observed arising from the various strong fundamental vibrations being probed. In some cases, peaks from vibrational combination and overtone bands are also observed. In principle, measurement of the frequencies of these various peaks and their relative intensities, such as might be obtained from a Fourier-transform infrared radiometer deployed in the field, provides sufficient information to identify a chemical agent and determine its concentration. The similarity in the chemical structures of sarin, soman, and DMMP lead to infrared spectra which are close in appearance, as seen in Figure 3, increasing the difficulty of discriminating between these agents and simulants.

Further challenging the use of microwave and millimeterwave measurements for the detection of chemical agents are the small absorption strengths in this spectral window relative to the infrared. Near room temperature, the ratio of the infrared to microwave-tomillimeterwave molecular band strengths is approximately given by,

$$
\frac{I_{I R}}{I_{M W}}=\frac{k T v_{I R} \mu_{I R}^{2}}{v_{M W}{ }^{2} \mu_{M W}{ }^{2}}
$$

where $k$ is the Boltzmann constant, $T$ is the gas temperature, $v_{I R}$ is the infrared frequency, $\mu_{I R}$ is the magnitude of the infrared transition dipole moment, $\nu_{M W}$ is the microwave frequency, and $\mu_{M W}$ is the magnitude of the microwave or millimeterwave transition dipole moment. For a typical infrared frequency of $1000 \mathrm{~cm}^{-1}$, infrared transition dipole moment of $3.3 \times 10^{-31} \mathrm{Cm}[0.1 \mathrm{D}]$, microwave-to-millimeterwave band peak frequency of $10 \mathrm{~cm}^{-1}$, and microwave or millimeterwave transition dipole moment of $3.3 \times 10^{-30} \mathrm{Cm}$ [1.0 D], the calculated ratio of $I_{I R} / I_{M W}$ is approximately 20, providing a significant advantage to infrared-based techniques over microwave-based techniques for the detection of chemical agents. Because the infrared and microwave-to-millimeterwave intensities are proportional to agent concentration, approximately 20 times greater agent concentration is required in the microwave region relative to the infrared region to obtain similar optical thicknesses or opacities.

The spectroscopic signatures of chemical agents dispersed as aerosols will also differ significantly between the microwave-to-millimeterwave and infrared spectral regions. The scattering will be significantly smaller in the microwave and millimeterwave region than in the infrared because of the approximate factor of 100 difference in wavelengths, $\lambda_{\mathrm{MW}-\mathrm{MM}}>1000 \mu \mathrm{m}$ and $\lambda_{\mathrm{IR}} \approx 10 \mu \mathrm{m}$ and the small size of aerosol particles of typically less than $10 \mu \mathrm{m}$ relative to microwave and millimeterwave wavelengths. Aerosol particles will mainly attenuate the microwave and millimeterwave radiation through absorption.

To quantitatively assess the utility of using microwave and millimeterwave spectroscopy for the standoff detection of chemical agents, below we theoretically model the detection of a chemical-agent gaseous cloud using passive sensing. 


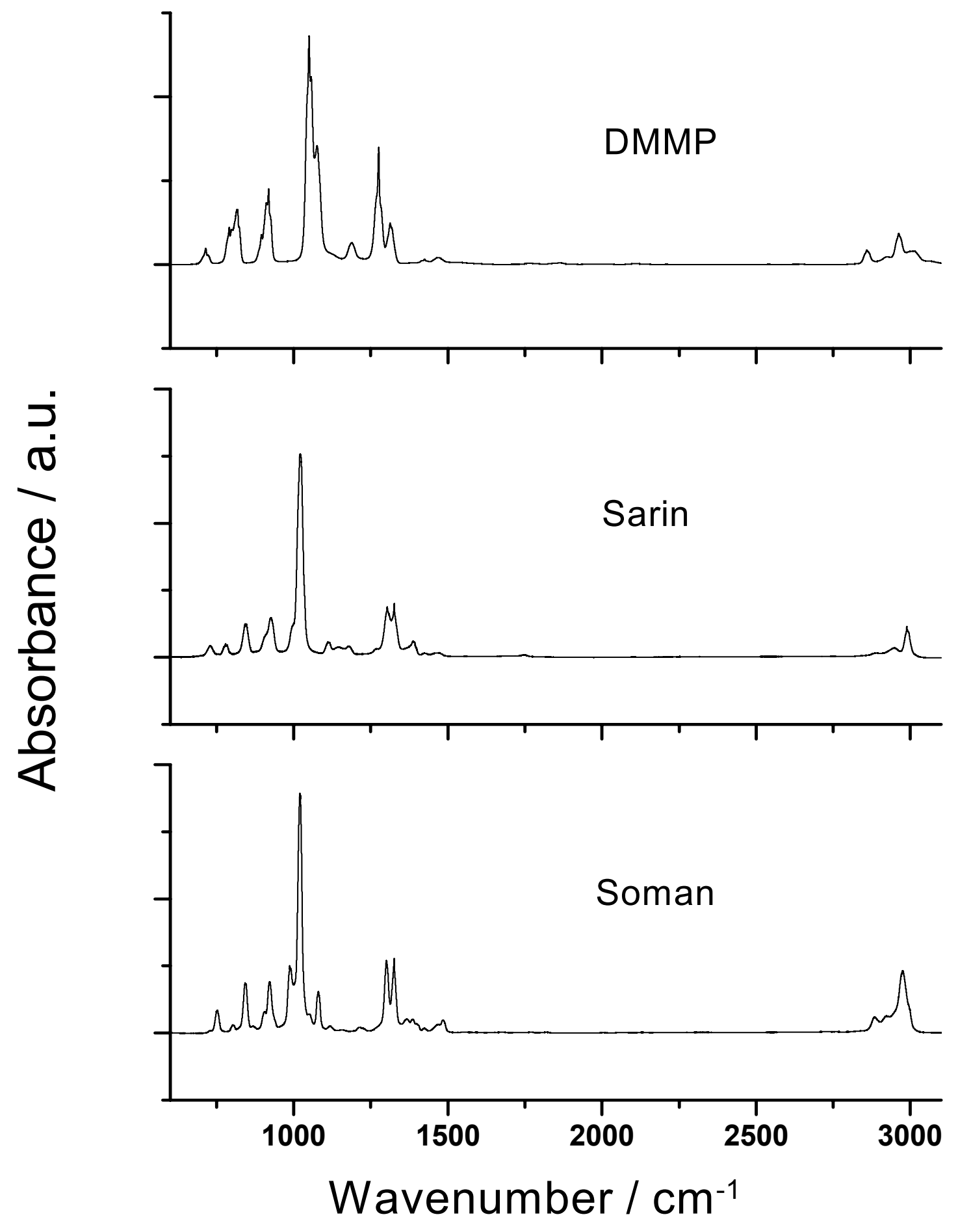

Figure 3. Infrared spectra of soman, sarin, and dimethyl methylphosphonate (DMMP) [13-15]. 


\section{RADIATIVE TRANSFER MODELING}

In principle, radiometry can be used to measure the change in the background microwave and millimeterwave radiance due to the presence of a gaseous or aerosol chemical-agent cloud. The magnitude of this change and its variation with wavelength provides quantitative information on the amount and type of chemical agent present. In the infrared, radiative-transfer theory has been successfully applied to the modeling of the infrared signatures of chemical agents [17-19], as well as biological-agents [20]. The present section applies a similar radiative-transfer model to microwave and millimeterwave chemical signatures to assess the potential of these techniques for the detection of chemical agents.

The case of an upward-looking passive radiometer peering through the atmosphere is a problem of interest to radio astronomers for understanding the effect of atmospheric transmission on their measurements. A theoretical investigation of this problem, directed at radioastronomy applications, has been presented in detail by Waters [21]. Below, we use this radiative-transfer model, which is also described in Reference [22], as a starting point for our theoretical analysis. It should be noted that the model of Waters has served as a foundation for more sophisticated models by Liebe [23-25] and others.

\section{Description of Model}

We assume a ground-level microwave or millimeterwave radiometer looking through the atmosphere at some zenith angle, $\theta_{\text {zenith }}$, as pictured in Figure 4. Here, $\theta_{\text {zenith }}=90^{\circ}$ corresponds to a horizontal view. The azimuthal pointing direction is ignored as the results are effectively independent of the value of this angle.

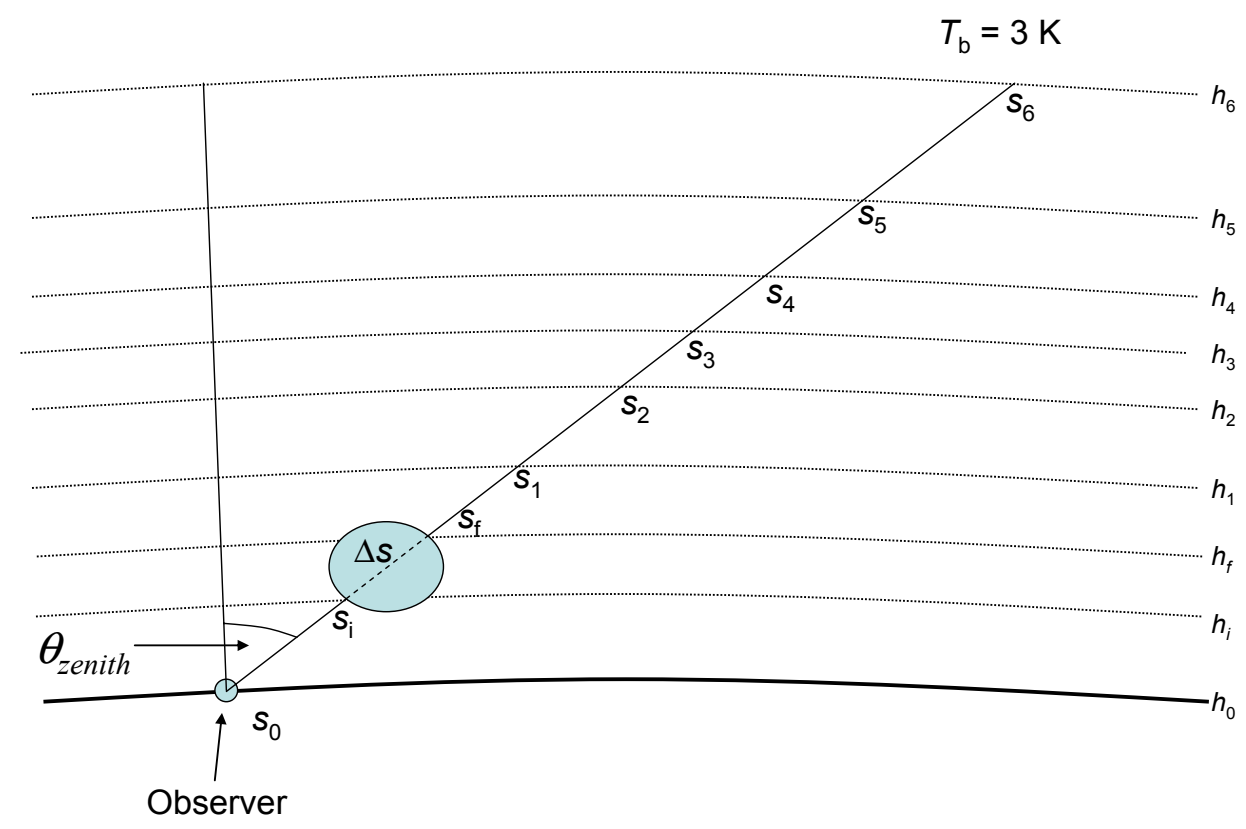

Figure 4. Diagram describing the radiative-transfer model. The shaded area indicates a chemicalagent cloud. 
As seen in Figure 4, the atmosphere is divided into six horizontal spherical layers in the absence of a chemical cloud, and eight when a chemical cloud is present. The six cloudfree layers, $\left\{\left[\mathrm{h}_{i}, \mathrm{~h}_{i+1}\right] \mid i=0,5\right\}$, are $[0,11.019 \mathrm{~km}],[11.019 \mathrm{~km}, 20.063 \mathrm{~km}],[20.063 \mathrm{~km}$, $32.162 \mathrm{~km}],[32.162 \mathrm{~km}, 47.349 \mathrm{~km}],[47.349 \mathrm{~km}, 51.411 \mathrm{~km}]$, and [51.411 km,

$60.000 \mathrm{~km}$ ], where the distances are actual/geometric altitudes above the surface and are based on the layer structure of the 1976 U.S. Standard Atmosphere, except that we only extend the upper reaches of the atmosphere to $60 \mathrm{~km}$ instead of $86 \mathrm{~km}$ due to the low gas density and concomitant high microwave transparency found above $60 \mathrm{~km}$. It should be noted that the U.S. Standard Atmosphere is defined in terms of geopotential altitudes, $h_{\text {geo }}$, which are related to the actual/geometric altitudes, $h_{\text {alt }} \equiv h_{i}$ shown in the figure by $h_{\text {geo }}=\left(h_{\text {alt }} R_{\text {Earth }}\right) /\left(h_{\text {alt }}+R_{\text {Earth }}\right)$. Associated with each layer transition, $h_{i}$, is a point, $s_{i}$, along the line of site of the radiometer where,

$$
s_{i}=-R_{\text {Earth }} \cos \theta_{\text {zenith }}+\sqrt{R_{\text {Earth }}^{2} \cos ^{2} \theta_{\text {zenith }}+2 h_{i} R_{\text {Earth }}+h_{i}^{2}}
$$

Here, $R_{\text {Earth }}=6369 \mathrm{~km}$ is the radius of the Earth.

For simplicity, atmospheric refraction is ignored. Refraction adds curvature to the atmospheric path, thus increasing the atmospheric pathlength for non-zero zenith angles. We have calculated this increase for paths which terminate at an altitude of $h_{\text {alt }}=60 \mathrm{~km}$ using,

$$
S_{\max }=\int_{0}^{h_{\text {alt }}}\left(R_{\text {Earth }}+h\right)\left\{R_{\text {Earth }}^{2}\left[1-\left(\frac{n_{0}}{n_{h}}\right)^{2} \sin ^{2} \theta_{\text {zenith }}\right]+2 h R_{\text {Earth }}+h^{2}\right\}^{-\frac{1}{2}} d h .
$$

Here, $n_{h} \equiv n(h)$ is the index of refraction of the atmosphere at altitude $h$ and is discussed by Crane [26], $n_{0} \equiv n(0)$ is the index of refraction of the atmosphere at ground level, and $\theta_{\text {zenith }}$ is the initial zenith angle. Solving for $s_{\max }$ numerically, we find that the atmospheric pathlength is increased by approximately $0.02 \%$ for a a zenith angle of $50^{\circ}$ and by $4 \%$ for a zenith angle of $90^{\circ}$. The atmospheric pathlength in the absence of diffraction is $93 \mathrm{~km}$ for a zenith angle of $50^{\circ}$ and $876 \mathrm{~km}$ for a zenith angle of $90^{\circ}$.

The radiative-transfer equation for the brightness temperature, $T_{v}\left(s_{0}\right)$, seen by the observer looking along a linear optical path from $s_{0}$ to $s_{6}$, as pictured in Figure 4 , takes the form [21],

$$
T_{v}\left(s_{0}\right)=T_{v}\left(s_{6}\right) e^{-\tau_{v}\left(s_{0}, s_{6}\right)}+\int_{s_{0}}^{s_{6}} T_{v}(s) k_{v}(s) e^{-\tau_{v}\left(s_{0}, s\right)} d s
$$

where $\tau_{\mathrm{v}}\left(s_{a}, s_{b}\right)$ is the optical depth or opacity defined by, 


$$
\tau_{v}\left(s_{a}, s_{b}\right)=\int_{s_{a}}^{s_{b}} k_{\nu}(s) d s
$$

Here, $k_{v}(\mathrm{~s})$ is the absorption coefficient, which varies along the path. The subscript $v$ indicates that Equations 5 and 6 must be solved for each frequency, $v$, in the spectral band of interest.

In formulating Equation 5, the Rayleigh-Jeans approximation has been used to express the radiative-transfer equation in terms of radiance temperatures instead of radiances. At $300 \mathrm{GHz}$ and $288.15 \mathrm{~K}$, radiances calculated by the exact Planck equation and by the Rayleigh-Jeans approximation agree within $3 \%$. At lower frequencies, the agreement is even better. For example, at $30 \mathrm{GHz}$ they agree to within $0.25 \%$. Given a radiance level at $300 \mathrm{GHz}$ from a radiating source near $288 \mathrm{~K}$, the Rayleigh-Jeans approximation will give a brightness temperature approximately $7 \mathrm{~K}$ lower than the exact Plank equation. Again, at lower frequencies the error is even smaller, being less than $1 \mathrm{~K}$ at $30 \mathrm{GHz}$. That we are primarily interested in differences in brightness temperatures, rather than accurate absolute brightness temperatures allows us to use this approximation.

The physical interpretation of Equation 5 is as follows. The first term in the equation gives the reduction in the apparent background radiance temperature, $T_{v}\left(s_{6}\right)$, as seen by the observer, due to absorption of the emitted radiance along the optical path. This background radiance is assumed to be dominated by the $3 \mathrm{~K}$ top-of-the-atmosphere cosmic background radiation from space. The second term in Equation 5 accounts for the increase in the brightness temperature seen by the observer due to blackbody emission by the atmospheric gases and aerosols along the optical path. The blackbody emission from point $s$ reaching the observer is characterized by a brightness temperature, $T_{V}(s)$, modulated by the absorption coefficient, $k_{v}(s)$, and reduced by the atmospheric absorption between the point of emission, $s$, and the point of observation, $s_{0}$.

The radiative-transfer equation was solved on a frequency grid of $0.25 \mathrm{GHz}$ over the frequency interval from $0 \mathrm{GHz}$ to $300 \mathrm{GHz}$. At each frequency of interest, Equation 5 was solved by breaking the integrals of Equations 5 and 6 into a sum of integrals over the individual spherical layers, $\left[s_{i}, s_{i+1}\right]$, using Gaussian quadratures of order 24 to 108 , with the higher-order quadratures required for the longer atmospheric paths near $\theta_{z e n i t h}=90^{\circ}$. Tests for convergence included looking for stabilization of the brightness temperature, $T_{\mathrm{v}}\left(s_{0}\right)$, as the quadrature order was increased and ensuring that $T_{\mathrm{v}}\left(s_{0}\right)$ never exceeded the maximum value of $T_{v}(s)$ along the path.

To calculate $T_{v}(s)$ and $k_{v}(s)$ necessary for finding a solution to Equation 5 we use the 1976 U.S. Standard Atmosphere, which is similar to the 1960 version used by Waters. The temperature profile, $T_{v}(s)$, is specified as part of the U.S. Standard Atmosphere. To calculate $k_{v}(s)$, we sum at each point $s$, the absorption coefficients for each atmospheric constituent, including any chemical agent present. The critical atmospheric microwave 
and millimeterwave absorbers are water vapor, $\mathrm{O}_{2}$, and the collision-induced continuum. Spectrally narrow emission lines from stratospheric ozone characterized by an emission temperature near $220 \mathrm{~K}$ and an emission altitude between $20 \mathrm{~km}$ to $30 \mathrm{~km}$ are also present. Their weak intensity and narrow pressure broadened widths of less than approximately $125 \mathrm{MHz}$ (HWHM, half width at half maximum) together with the extinction of their downward emission by atmospheric water vapor limits their contribution to the signal from a broad-band microwave or millimeterwave radiometer.

Both water vapor and $\mathrm{O}_{2}$ have discrete molecular absorptions in the microwave-tomillimeterwave region. The collision-induced continuum arises primarily from collisions between water-vapor molecules or between water vapor and $\mathrm{O}_{2}$ and $\mathrm{N}_{2}$ molecules. Nitrogen, the major atmospheric constituent, has no significant discrete absorptions in the microwave or millimeterwave spectral regions, but does contribute to the collisional processes responsible for the pressure broadening of the $\mathrm{O}_{2}$ and water-vapor discrete absorptions and for the underlying continuum dominated by collisional processes involving water molecules.

The other minor constituents of the atmosphere, included battleground emission gases, were ignored in the present modeling. We note that many of the background gases from gasoline and kerosene vapors, such as hydrocarbons, and their combustion products have small electric dipole moments and are thus not expected to significantly interfere with the detection of chemical agents. At the long wavelengths of the microwave and millimeterwave radiation, molecular Rayleigh and background atmospheric aerosol scattering and emission are expected to be small and thus were not included in the modeling.

Calculation of the contribution of each of the constituents to $k_{\Downarrow}(s)$ requires knowledge of their partial pressure or density as a function of $s$ and their absorption coefficients at that pressure or density. Below we summarize the calculation of the absorption coefficient for oxygen, water vapor, and the chemical agent.

\section{Oxygen}

For oxygen, partial-pressure information is obtained directly from the pressure profile of the U.S. Standard Atmosphere by assuming a mole fraction of 0.21 . Following Waters [21], the absorption coefficient for molecular oxygen in $\mathrm{cm}^{-1}$ is obtained from,

$$
\begin{gathered}
k_{v}^{O_{2}}=1.44 \times 10^{-5} p T^{-3} v \sum_{N \text { odd }}\left\{g_{N+}\left|\phi_{N+}\right|^{2} v_{N+} f\left(v, v_{N+}\right)+\right. \\
\left.g_{N-}\left|\phi_{N-}\right|^{2} v_{N-} f\left(v, v_{N-}\right)+\frac{1}{2} g_{N_{0}}\left|\phi_{N_{0}}\right|^{2} F(v)\right\} e^{-E_{N} / k T},
\end{gathered}
$$

where $p$ and $T$ are the pressure in millibar and temperature in kelvin, respectively, at point $s$ along the optical path, $f$ and $F$ are lineshape functions defined by 
$f\left(v, v_{0}\right)=\frac{1}{\pi} \frac{4 v v_{0} \Delta v}{\left(v_{0}^{2}-v^{2}\right)^{2}+4 v^{2} \Delta v^{2}}$

and

$F(v)=\frac{2}{\pi} \frac{v \Delta v}{\left(v^{2}+\Delta v^{2}\right)}$

The $g_{N^{+}}\left|\phi_{N^{+}}\right|^{2}, g_{N_{-}}\left|\phi_{N_{-}}\right|^{2}$, and $g_{N_{0}}\left|\phi_{N_{0}}\right|^{2}$ are linestrength factors, including degeneracies, for $\Delta J=+1, \Delta J=-1$, and $\Delta J=0$ transitions, respectively, where $J$ is the total angular momentum and $N$ is the rotational angular momentum for the molecule:

$$
\begin{aligned}
& g_{N-}\left|\phi_{N-}\right|^{2}=\frac{(N+1)(2 N-1)}{N} \\
& g_{N+}\left|\phi_{N+}\right|^{2}=\frac{N(2 N+3)}{N+1} \\
& g_{N_{0}}\left|\phi_{N_{0}}\right|^{2}=\frac{2\left(N^{2}+N+1\right)(2 N+1)}{N(N+1)} .
\end{aligned}
$$

The half-width-half-maximum (HWHM) linewidth parameter, $\Delta v$, used in Equations 8 and 9 is also a function of $s$ through its pressure and temperature dependence. $\Delta v$ in $\mathrm{GHz}$ is given as a function of the pressure $p$ in millibar and temperature $T$ in kelvin by the following expressions where $\Delta v_{\mathrm{B}}=0.0527 \mathrm{GHz}$ :

$$
\begin{array}{ll}
\Delta v=1.41 \times 10^{-3} p(300 / T) & \Delta v \leq \Delta v_{\mathrm{B}} \\
\Delta v=\frac{1}{3}\left(1.41 \times 10^{-3}\right) p(300 / T)+\frac{2}{3}(0.0527) & \Delta v \geq \Delta v_{\mathrm{B}}
\end{array}
$$

\section{Water Vapor}

For water vapor, we follow Waters [21], and approximate the water-vapor density, $\rho_{\text {water }}\left(h_{\text {alt }}\right)$, as a function of altitude, $h_{\text {alt }}$, by,

$$
\rho_{\text {water }}\left(h_{\text {alt }}\right)=\rho_{\text {water }}(0) \exp \left(-h_{\text {alt }} / h_{\text {scale }}\right)
$$

where the ground-level density is $\rho_{\text {water }}(0)=10 \mathrm{~g} / \mathrm{m}^{3}$ and the scale height is $h_{\text {scale }}=2 \mathrm{~km}$. The $\rho_{\text {water }}(0)$ density corresponds to a relative humidity of $77 \%$ at the boundary-layer or ground-level temperature of $288.15 \mathrm{~K}$. For altitudes above $h_{\text {alt }}=15 \mathrm{~km}$, the water-vapor 
concentration is assumed to be constant at $2 \mathrm{ppm}(2 \mu \mathrm{mole} / \mathrm{mole})$. Note that the total amount of precipitable water vapor is given approximately by $\rho_{\text {water }}(0) h_{\text {scale }}=2 \mathrm{~g} / \mathrm{cm}^{2}$ or just $2 \mathrm{~cm}$ since the density of water is $1 \mathrm{~g} / \mathrm{cm}^{3}$.

The absorption coefficient for water vapor in $\mathrm{cm}^{-1}$ was modeled using,

$$
k_{v}^{H_{2} O}=1.44 \rho_{\text {water }} T^{-3 / 2} v \sum_{\text {transitions }}\left\{e^{-E_{l} / k T}-e^{-E_{l} / k T}\right\} g_{\ell}\left|\phi_{l m}\right|^{2} f\left(v, v_{l m}\right),
$$

where the water-vapor density is in $\mathrm{g} / \mathrm{m}^{3}$, frequencies are in $\mathrm{GHz}$, and $f\left(v, v_{l m}\right)$ is defined in Equation 8. Terms which vary with altitude and thus with $s$ include $\rho_{\text {water }}, T$, and $f\left(v, v_{l m}\right)$ through the linewidth parameter defined below. Values for the various spectroscopic constants characterizing the rotational transitions for water vapor, i.e., the state degeneracies $g_{l}$, the upper and lower state energies, $E_{m}$ and $E_{l}$, and the square magnitude of the direction cosine matrix element, $\left|\phi_{l m}\right|^{2}$, have been tabulated by Waters [21] and are reproduced in Appendix 2 for convenience. Improved values for many of the parameters are available in the literature or from the HITRAN atmospheric database [27].

The water-vapor linewidth parameter [21] for transition $m \leftrightarrow l$, is approximated by,

$$
\Delta v_{l m}=\Delta v_{l m}^{0}\left(\frac{p}{1013}\right)\left(\frac{T}{300}\right)^{-x}\left[1+4.6 \times 10^{-3} \frac{\rho_{\text {water }} T}{p}\left(\frac{\Delta v_{l m}\left(\mathrm{H}_{2} \mathrm{O}\right)}{\Delta v_{l m}^{0}}-1\right)\right],
$$

where $p$ is the total pressure in millibar, $\rho_{\text {water }}$ is the water vapor density in $\mathrm{g} / \mathrm{m}^{3}$, and the parameters $x, \Delta v_{l m}{ }^{0}$, and $\Delta v_{l m}\left(\mathrm{H}_{2} \mathrm{O}\right)$ are as listed in Appendix 2. The correction factor of Gaut and Reifenstein [28] discussed by Water's was also included [21]. This correction factor takes the form,

$$
\Delta k_{v}=1.08 \times 10^{-11} \rho_{\text {water }}\left(\frac{300}{T}\right)^{2.1}\left(\frac{p}{1000}\right) v^{2},
$$

where the parameters and their units have been defined above. The correction factor accounts for the water-vapor continuum induced by water-water collision (self continuum) and by water-nitrogen or water-oxygen collisions (foreign-gas continuum).

\section{Chemical Agent}

The chemical-agent cloud was modeled by assuming a constant molar atmospheric concentration of agent between points $s_{i}$ and $s_{f}$ along the atmospheric line of site. Thus, the cloud is assumed to be free of any aerosolized chemical agent. The absorption coefficient for the chemical agent was calculated with the same model used to generate the absorbance curves of Figure 2. The absorption coefficient was generated on a 
$0.1 \mathrm{GHz}$ grid between $0 \mathrm{GHz}$ and $300 \mathrm{GHz}$. Linear interpolation was used to obtain values for the absorption coefficient between points.

\section{MODEL RESULTS}

In Figure 5 we show the calculated brightness temperature, $T_{v}(0)$, as a function of frequency from $0 \mathrm{GHz}$ to $300 \mathrm{GHz}$ for a ground-based, upward-looking radiometer viewing at a zenith angle, $\theta_{\text {zenith }}=0$. Calculations are given with and without the presence of a cloud of $1 \mu \mathrm{mol} / \mathrm{mol}[1 \mathrm{ppm}]$ of the simulant dimethyl methyl phosphonate (DMMP) in the background air. The cloud is assumed to reside between $1 \mathrm{~km}$ and $2 \mathrm{~km}$ in altitude above the surface, mimicking a dispersal event from a low-flying airplane. The horizontal extent of the cloud is assumed to fill the field-of-view (FOV) of the radiometer.

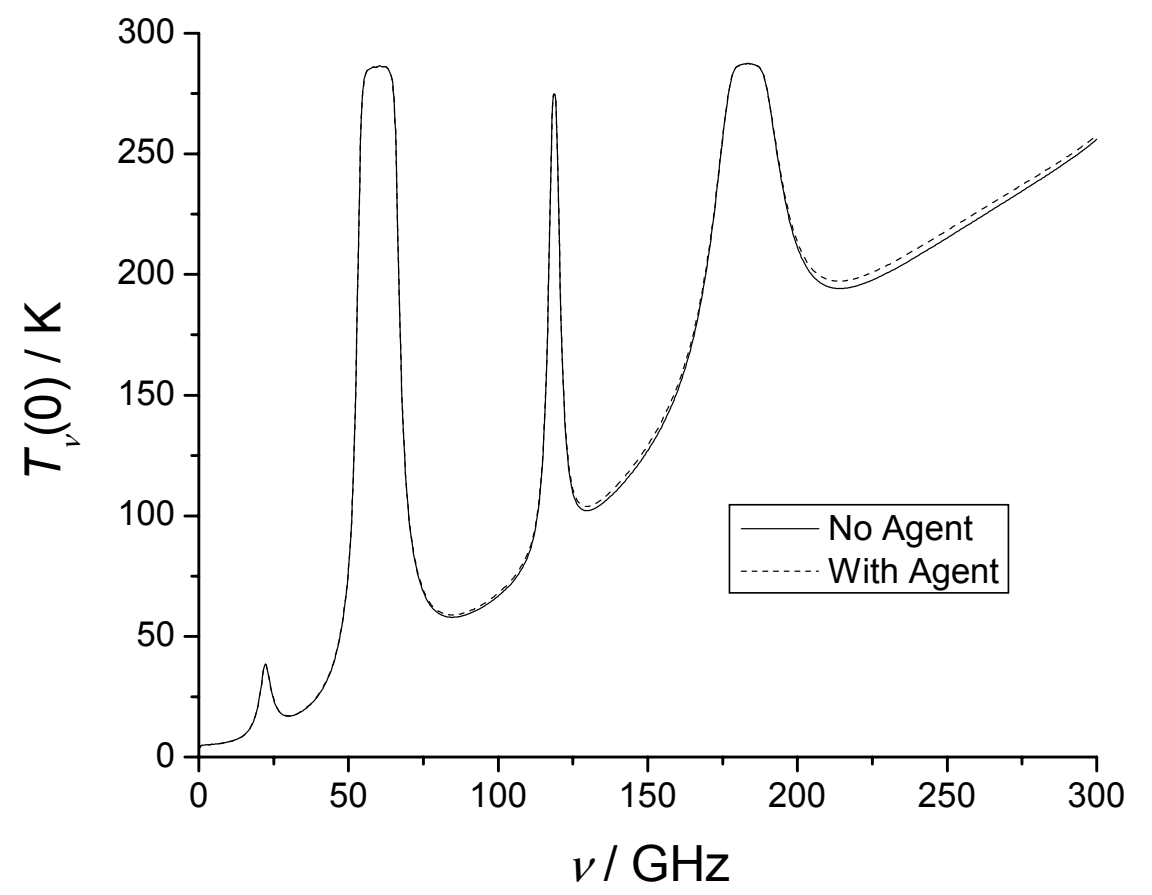

Figure 5. Brightness temperature as a function of frequency for a ground-based, vertical-looking radiometer. Temperatures are shown when no chemical agent is present and when $1 \mu \mathrm{mol} / \mathrm{mol}$ [1 ppm] DMMP, a nerve-agent simulant, is present as a $1 \mathrm{~km}$ thick cloud lying between $1 \mathrm{~km}$ and $2 \mathrm{~km}$ in altitude.

The dominant discrete spectral features in Figure 5 are $\mathrm{O}_{2}$ lines near $60 \mathrm{GHz}$ and $119 \mathrm{GHz}$ and water-vapor lines near $22 \mathrm{GHz}$ and $183 \mathrm{GHz}$. The calculated brightness temperatures are dominated by contributions from the lowest atmospheric layer, i.e., $\left[h_{0}, h_{1}\right]$ of Figure 4 . This statement is supported by Figure 6 which gives the contributions to the total brightness temperature from each of the horizontal layers $\left\{\left[h_{i}, h_{i+1}\right] \mid i=0,5\right\}$ as calculated from the dominant second term of Equation 5. The results from this figure support the neglect of atmospheric layers above $60 \mathrm{~km}$ in the present modeling, and indeed probably above $20 \mathrm{~km}$. 


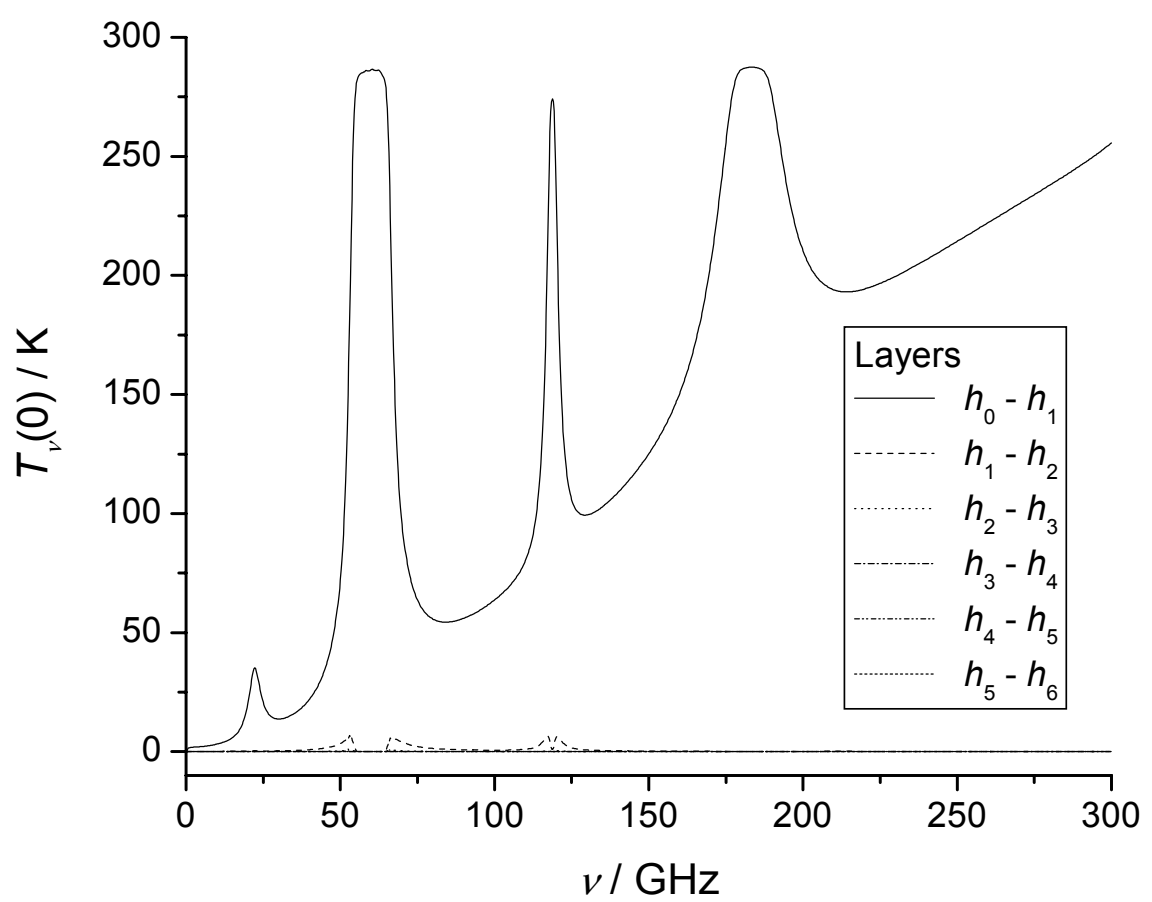

Figure 6. Contributions to the total brightness temperature observed by a ground-based radiometer looking at a zenith angle of $0^{\circ}$. The layer brightness temperatures are calculated using the dominant second term of Equation 5.

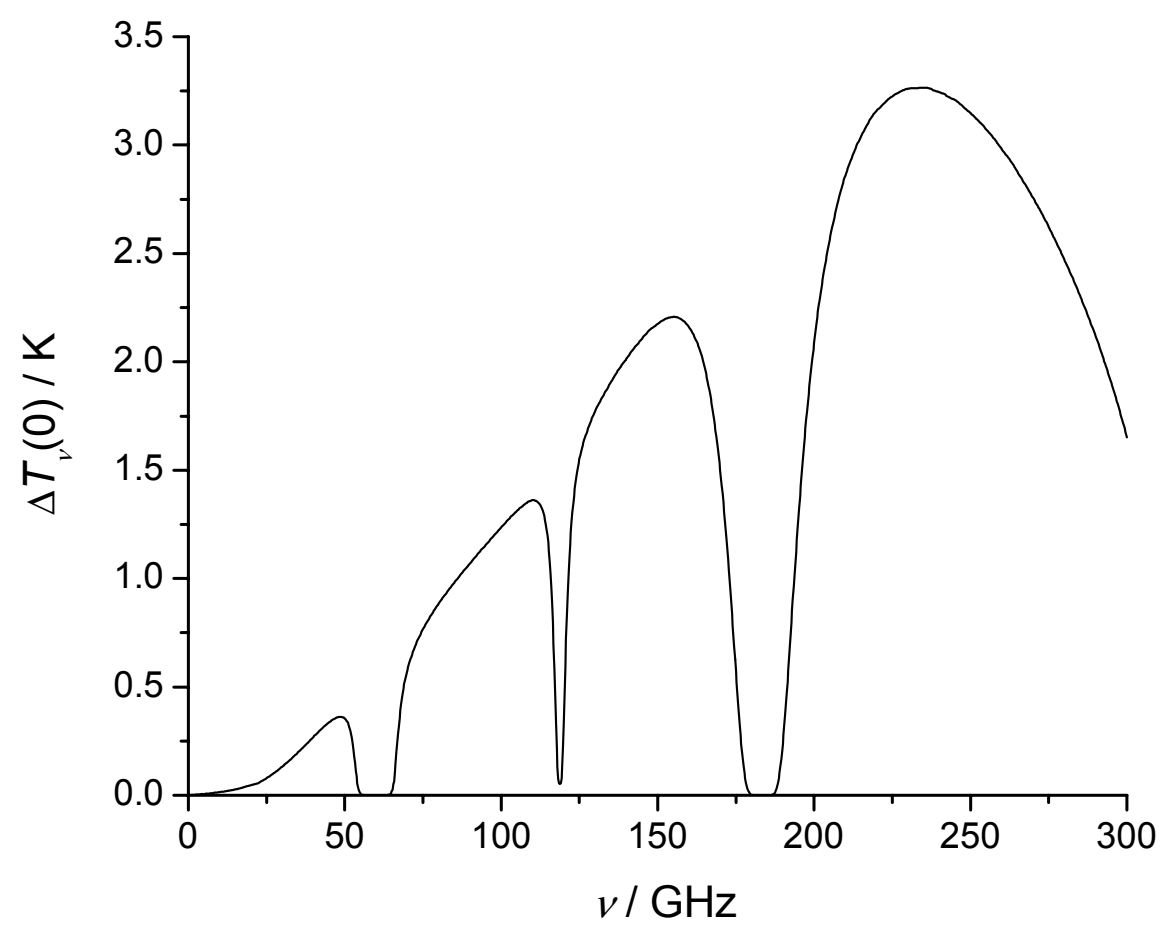

Figure 7. The difference between the brightness temperature with DMMP and without DMMP as a function of frequency as obtained from the calculations presented in Figure 5. 
The increased opacity due to the chemical agent leads to a slightly higher calculated brightness temperature when the chemical cloud is present, although it is still $\leq 288.15 \mathrm{~K}$, the surface-atmosphere boundary-layer temperature which is the highest temperature along the optical path. The broad spectral profile of the rotational contour of DMMP leaves no obvious characteristic signature in the spectrum of Figure 5 to aid chemical identification.

The effect of the simulant is seen more clearly in Figure 7 where the differences in the brightness temperatures between the agent and no agent spectra are plotted as a function of frequency. Figure 7 shows that the maximum calculated brightness temperature difference occurs near $225 \mathrm{GHz}$ and is slightly greater than $3 \mathrm{~K}$.

These brightness temperature differences depend upon both the agent concentration and the agent type, as illustrated in Figures 8 and 9. In Figure $8, \Delta T_{\sqrt{ }}(0)$ is plotted against the concentration-pathlength product, $C L$, for the two atmospheric windows at $v=150 \mathrm{GHz}$ and $v=225 \mathrm{GHz}$. The figure demonstrates that $C L$ is a nearly linear function of agent concentration. In Figure 9 the brightness temperature differences under the conditions used to produce Figure 7 are plotted for DMMP, sarin, and soman, each at $1 \mu \mathrm{mol} / \mathrm{mol}[1$ $\mathrm{ppm}]$. This figure shows that the appearance of the $\Delta T_{\mathrm{v}}(0)$ curves are very sensitive to agent type. The sarin plot of Figure 9 corresponds to a concentration-pathlength product of $C L=5.1 \mathrm{~g} / \mathrm{m}^{2}$, however the overall detection sensitivity will depend on a number of factors, including sensor performance and background variation and noise. Recall from the Introduction that the JSLCAD has a stated detection sensitivity of $C L=0.135 \mathrm{~g} / \mathrm{m}^{2}$ for a nerve agent [2]. In the next section microwave and millimeterwave detection sensitivities are more fully discussed.

The significant differences in the magnitudes of $\Delta T_{v}(0)$ for the various agents or stimulants in Figure 9 reflect the differences in the rotational band intensities shown in Figure 2. In principle, the shapes of these curves provide information on the identity of the chemical agent. To examine this possibility we consider a two-channel radiometer with spectral windows coincident with the atmospheric windows at $150 \mathrm{GHz}$ and $225 \mathrm{GHz}$. This choice for the two spectral windows allows significant overlap of the spectral windows with the rotational bands of the various agents or simulants, while minimizing contributions from the water-vapor continuum absorption which grows in intensity with frequency. For this two-channel radiometer, the calculated ratio, $\Delta T_{225 \mathrm{GHz}}(0) / \Delta T_{150 \mathrm{GHz}}(0)$, is found to vary significantly with agent, with $\Delta T_{225 \mathrm{GHz}}(0) / \Delta T_{150 \mathrm{GHz}}(0)=1.48,0.92$, and 0.69 for DMMP, sarin, and soman, respectively. 


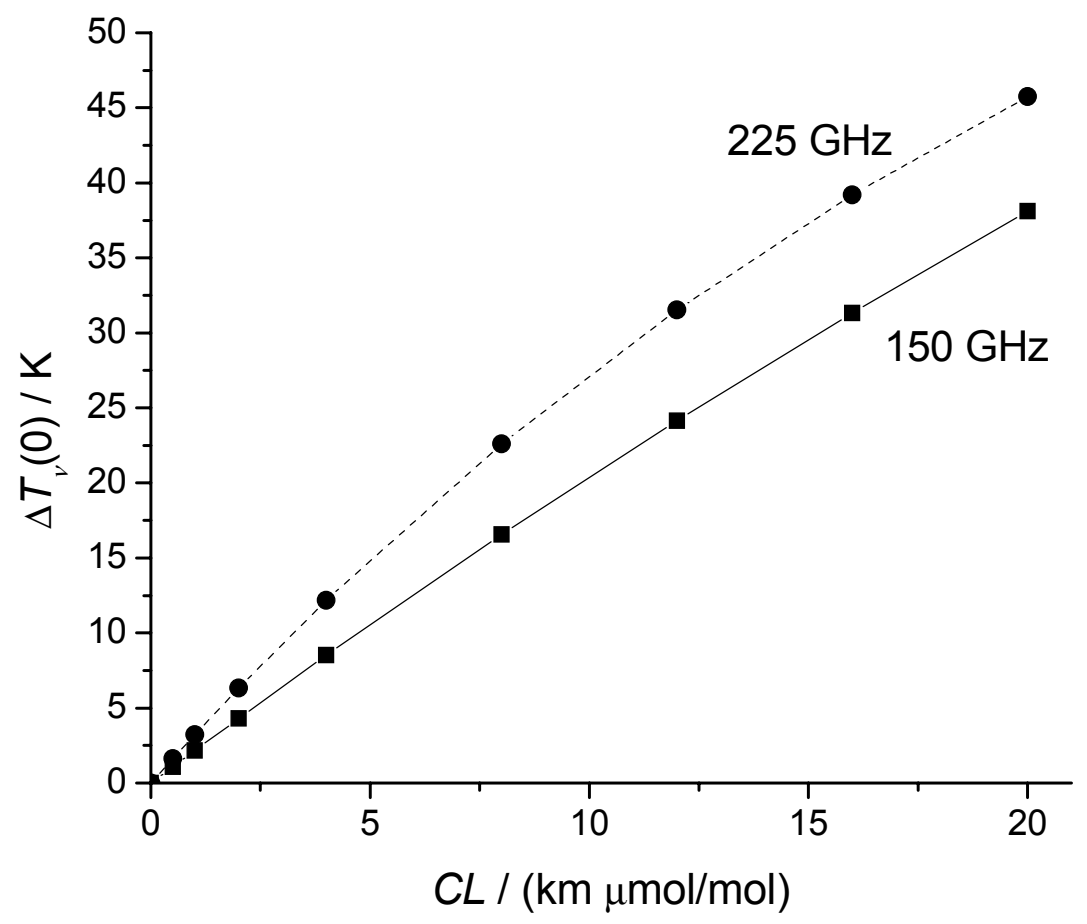

Figure 8. Plot of the brightness temperature difference versus the product of the agent concentration $(C)$ and the optical pathlength $(L)$ through the cloud for DMMP for the atmospheric windows at 150 GHz and 225 GHz.

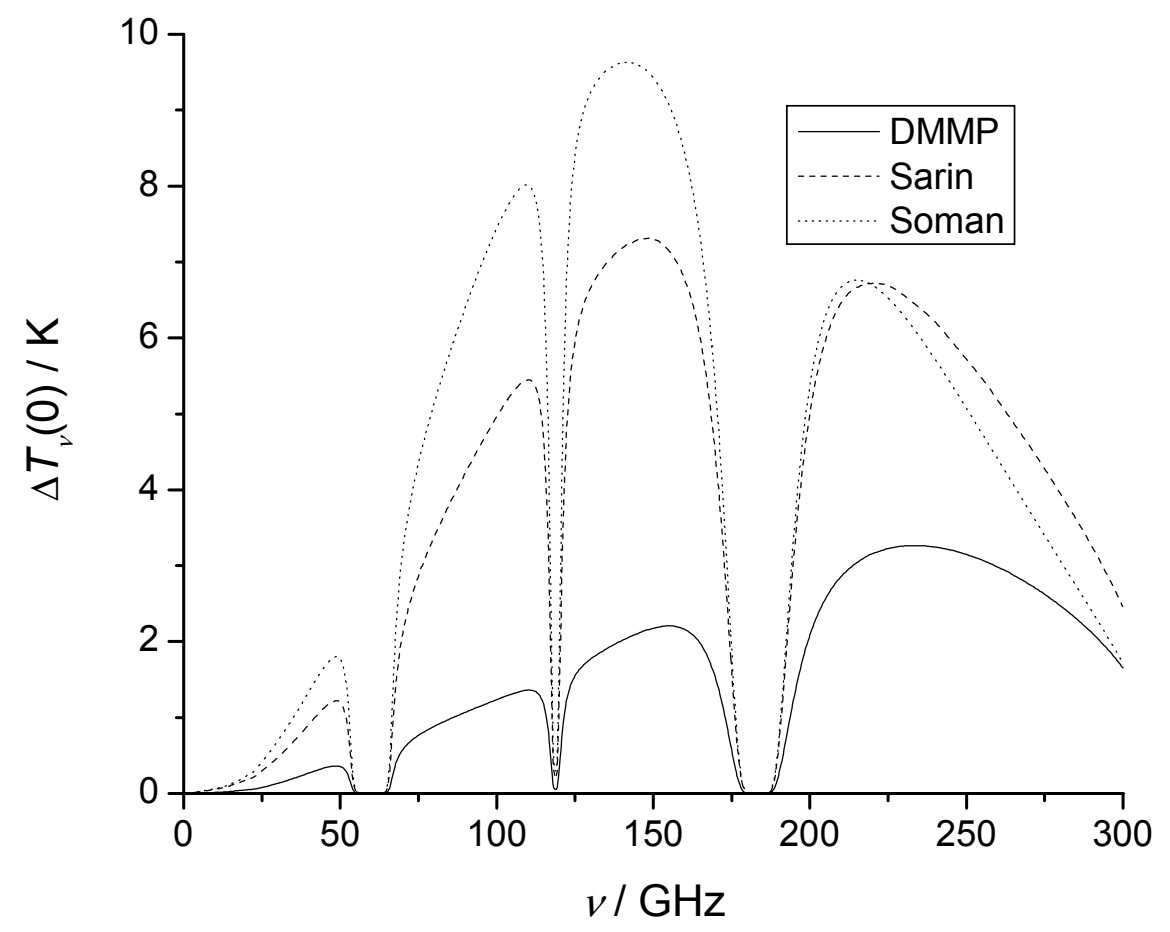

Figure 9. Plot showing the difference in brightness temperatures with and without agent or simulant for DMMP, sarin, and soman. The ground-level water-vapor concentration is $10 \mathrm{~g} / \mathrm{m}^{3}$, which corresponds to a relative humidity of $77 \%$ at $288.15 \mathrm{~K}$. 
Complicating agent identification is the sensitivity of $\Delta T_{\nu}(0)$ to the magnitude of the relative humidity. In Figure 10 we plot the brightness temperature as a function of frequency as before except that the water-vapor concentration, and thus relative humidity, is reduced by $50 \%$. This reduction corresponds to a change in $\rho_{\text {water }}(0)$ in Equation 15 from $10 \mathrm{~g} / \mathrm{m}^{3}$ to $5 \mathrm{~g} / \mathrm{m}^{3}$. The effect of this reduction is to significantly decrease the atmospheric opacity and associated brightness temperature relative to the $10 \mathrm{~g} / \mathrm{m}^{3}$ watervapor level, including in the atmospheric windows used in the calculation of $\Delta T_{225 \mathrm{GHz}}(0) / \Delta T_{150 \mathrm{GHz}}(0)$. This decrease in opacity affects the continuum brightness temperatures seen in Figures 5 and 10. For instance, at $300 \mathrm{GHz}$ the brightness temperature is $256 \mathrm{~K}$ for a $10 \mathrm{~g} / \mathrm{m}^{3}$ water-vapor level versus $195 \mathrm{~K}$ for a $5 \mathrm{~g} / \mathrm{m}^{3}$ watervapor level. A reduction by two in the lower-atmosphere water-vapor partial pressure changes $\Delta T_{225 \mathrm{GHz}}(0)$ from $3.23 \mathrm{~K}$ at $10 \mathrm{~g} / \mathrm{m}^{3}$ to $5.83 \mathrm{~K}$ at $5 \mathrm{~g} / \mathrm{m}^{3}$ and changes $\Delta T_{150 \mathrm{GHz}}(0)$ from $2.17 \mathrm{~K}$ at $10 \mathrm{~g} / \mathrm{m}^{3}$ to $2.89 \mathrm{~K}$ at $5 \mathrm{~g} / \mathrm{m}^{3}$, as seen from examination of Figures 9 and 11 , where the latter figure is the same as the former except that the water vapor concentration has been reduced by $50 \%$. In addition to the changes in the absolute temperatures, the ratios $\Delta T_{225 \mathrm{GHz}}(0) / \Delta T_{150 \mathrm{GHz}}(0)$ are also affected, becoming 2.01, 1.24, and 0.94 at $5 \mathrm{~g} / \mathrm{m}^{3}$ for DMMP, sarin, and soman, respectively, where previously they were $1.48,0.92$, and 0.69 at $10 \mathrm{~g} / \mathrm{m}^{3}$. The modeling shows that corrections will need to be applied for the atmospheric humidity to effectively use such a ratio radiometer for chemical-agent identification.

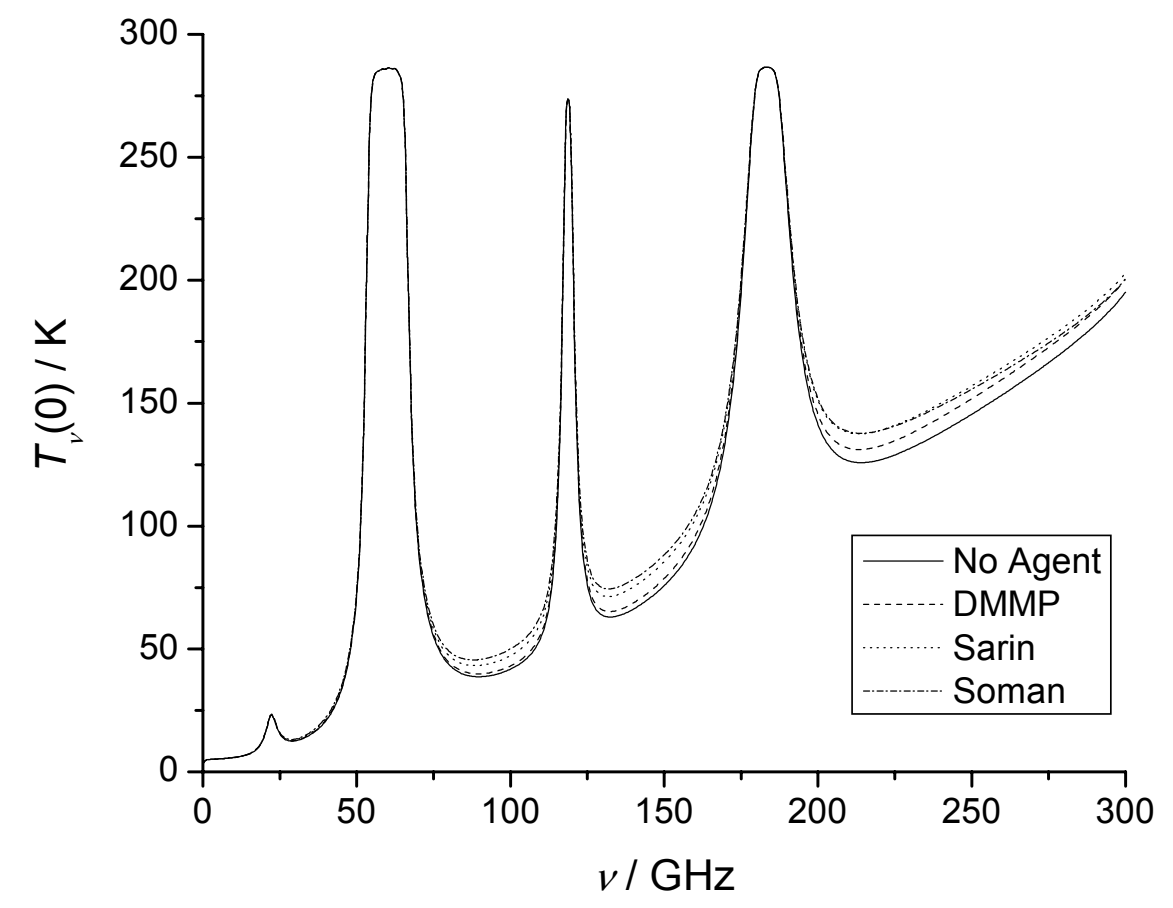

Figure 10. Brightness temperature as a function of frequency for a ground-level, vertical looking radiometer. The ground-level water-vapor concentration is $5 \mathrm{~g} / \mathrm{m}^{3}$. Spectra are shown without a chemical cloud and with $1 \mu \mathrm{mol} / \mathrm{mol}$ [1 ppm] chemical clouds of DMMP, sarin, and soman lying between $1 \mathrm{~km}$ and $2 \mathrm{~km}$ in altitude. 
The calculations above are for a vertical-viewing sensor, i.e. $\theta_{z e n i t h}=0^{\circ}$. This viewing geometry allows the greatest sensitivity for a chemical agent since it minimizes the optical pathlength through the optically thick, higher-density, lower-altitude portion of the atmosphere. A realistic sensor will typically be required to look for a chemical-agent release near ground level, at a horizontal viewing angle closer to $\theta_{\text {zenith }}=90^{\circ}$.

Consequently, a large fraction of the measured radiance and associated brightness temperature will come from emission from the optically thick, surface-atmosphere boundary layer, and not from the colder higher-altitude regions. As the brightness temperature saturates at the surface-atmosphere boundary-layer temperature the effective dynamic range of the radiometer is reduced, decreasing the sensitivity necessary for detection and identification of a chemical-agent cloud. In Figure 12 the predicted brightness temperature is plotted as a function of frequency for a series of 5 viewing angles between $0^{\circ}$ and $90^{\circ}$. In each case, the optical pathlength through the cloud is fixed at $1 \mathrm{~km}$ by constraining the chemical agent to reside between $s_{i}=1 \mathrm{~km}$ and $s_{f}=2 \mathrm{~km}$ in Figure 4 . These values correspond to $\left[h_{i}, h_{f}\right]$ values of $[1 \mathrm{~km}, 2 \mathrm{~km}],[0.866 \mathrm{~km}$, $1.732 \mathrm{~km}],[0.500 \mathrm{~km}, 1.000 \mathrm{~km}],[0.259 \mathrm{~km}, 0.518 \mathrm{~km}]$, and $[0.000 \mathrm{~km}, 0.000 \mathrm{~km}]$ for $\theta_{\text {zenith }}=0^{\circ}, 30^{\circ}, 60^{\circ}, 75^{\circ}$, and $90^{\circ}$, respectively. Most noteworthy in Figure 12 is the near complete saturation of the brightness temperatures at the surface-atmosphere boundarylayer temperature of $288.15 \mathrm{~K}$ for the horizontal viewing angle of $\theta_{\text {zenith }}=90^{\circ}$.

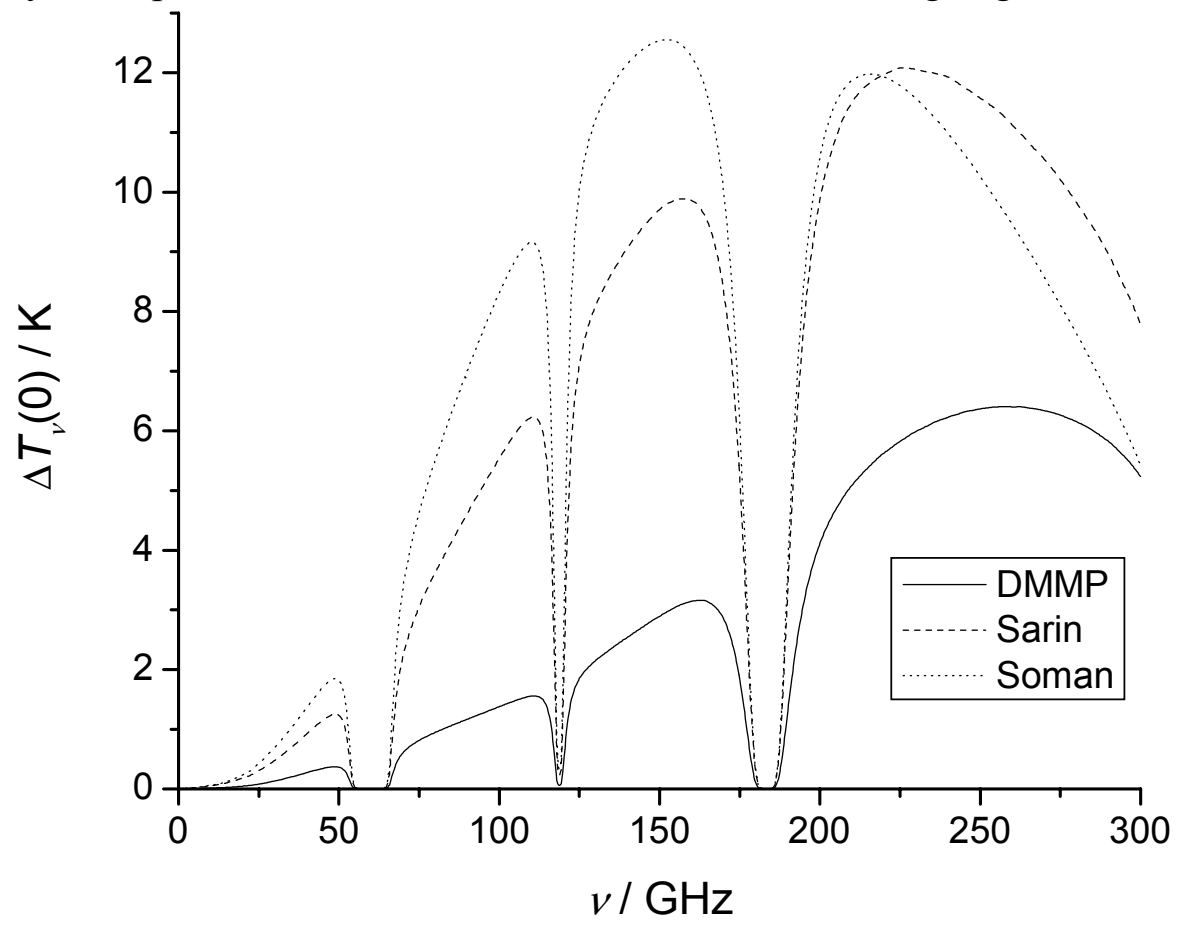

Figure 11. This plot is similar to that shown in Figure 8 except that the ground-level water-vapor concentration has been reduced by $50 \%$ to $5 \mathrm{~g} / \mathrm{m}^{3}$.

In Figure 13 we examine the sensitivity for the detection of a $1 \mu \mathrm{mol} / \mathrm{mol}[1 \mathrm{ppm}]$ chemical cloud of soman as measured by $\Delta T_{\mathcal{V}}(0)$, the difference in brightness temperature with and without an agent present. Results are presented for $\theta_{\text {zenith }}=75.0^{\circ}$ and $89.5^{\circ}$ and for ground-level water vapor concentrations of $5 \mathrm{~g} / \mathrm{m}^{3}$ and $10 \mathrm{~g} / \mathrm{m}^{3}$. Because of the near saturation of the brightness temperature at $\theta_{\text {zenith }}=89.5^{\circ}$ for a water-vapor level of 
$5 \mathrm{~g} / \mathrm{m}^{3}$, we have not included the uninteresting results for a $\theta_{z e n i t h}=89.5^{\circ}$ and a watervapor level of $10 \mathrm{~g} / \mathrm{m}^{3}$.

Figures 12 and 13 clearly indicate that ground-based passive microwave and millimeterwave chemical-agent sensors have a significantly reduced sensitivity, as measured by $\Delta T_{\mathcal{V}}(0)$, for the detection of chemical-agent clouds near ground level where horizontal or near horizontal pointing of the sensor is required. The next section examines the measurement of $\Delta T_{\Downarrow}(0)$ by a realistic sensor, to provide insight into the minimum $\Delta T_{\mathcal{V}}(0)$ signal required under realistic conditions for chemical agent detection and identification. A summary of the key findings from the present section include the following:

- For a ground-level, upward-viewing sensor the signal is dominated by contributions from the first $20 \mathrm{~km}$ of the atmosphere.

- $\Delta T_{\sqrt{ }}(0)$, the change in brightness temperature due to the presence of a chemical agent cloud, increases with decreasing humidity and decreases with increasing zenith angle.

- At a constant pathlength $(L), \Delta T_{\sqrt{ }}(0)$ increases approximately linearly with agent concentration $(C)$.

- $\Delta T_{\mathfrak{V}}(0)$ measurements must be corrected for relative humidity prior to determination of the chemical-agent concentration-pathlength product, $C L$.

- $\Delta T_{\sqrt{ }}(0)$ is predicted to be small, typically $<200 \mathrm{mK}$, for a horizontal or near horizontal viewing sensor, challenging the ability to detect a chemical-agent cloud or release near ground level using microwave or millimeterwave passive sensing.

- For a vertical pointing radiometer, a $\Delta T_{\nu}(0)$ greater than $12 \mathrm{~K}$ is possible for a $1 \mathrm{~km}$ thick, $1 \mu \mathrm{mol} / \mathrm{mol}[1 \mathrm{ppm}]$ chemical-agent cloud at $38 \%$ relative humidity.

- Multiple channel radiometers should be able to discriminate between different chemical agents. 


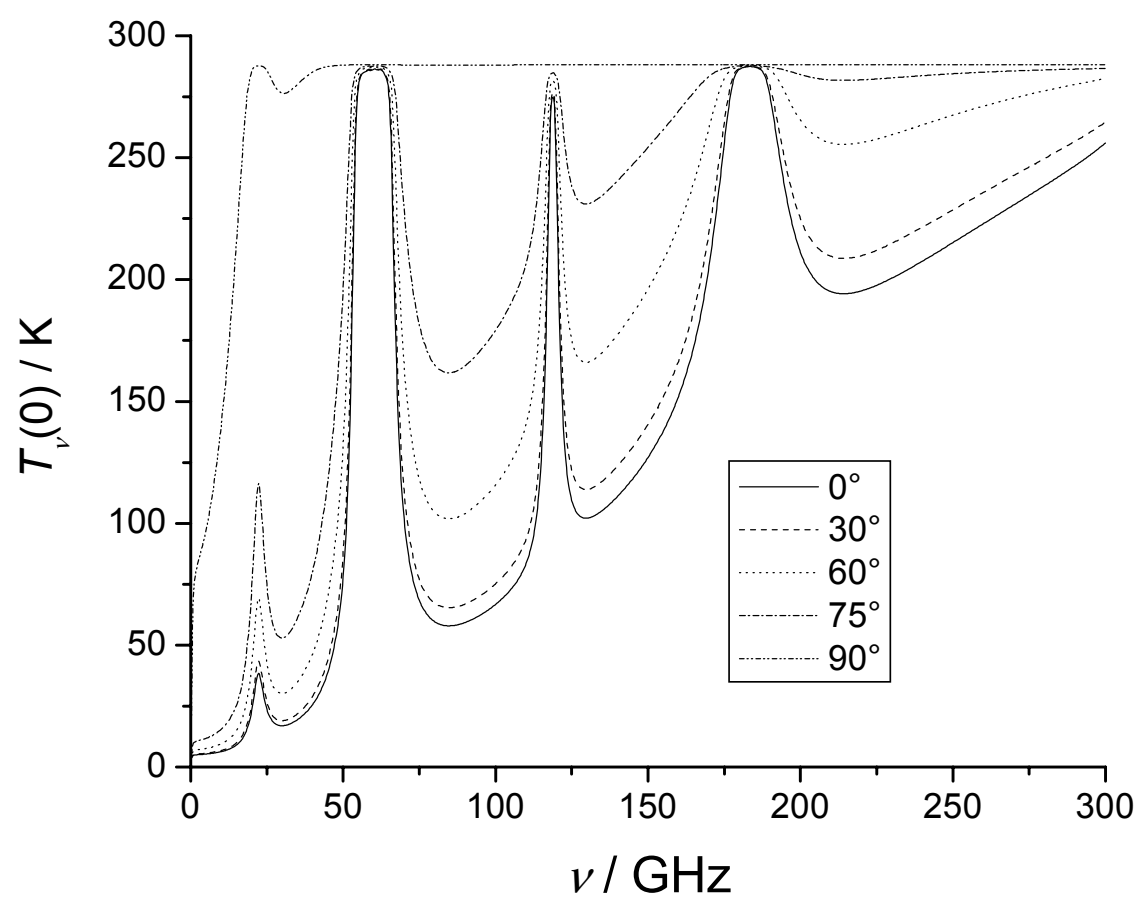

Figure 12. Brightness temperature as a function of frequency for various zenith angles from $0^{\circ}$ to $90^{\circ}$. Horizontal viewing corresponds to a zenith angle of $90^{\circ}$. The ground-level water-vapor concentration is $10 \mathrm{~g} / \mathrm{m}^{3}$, which corresponds to a relative humidity of $77 \%$ at the surface-atmosphere boundary layer temperature of $288.15 \mathrm{~K}$.

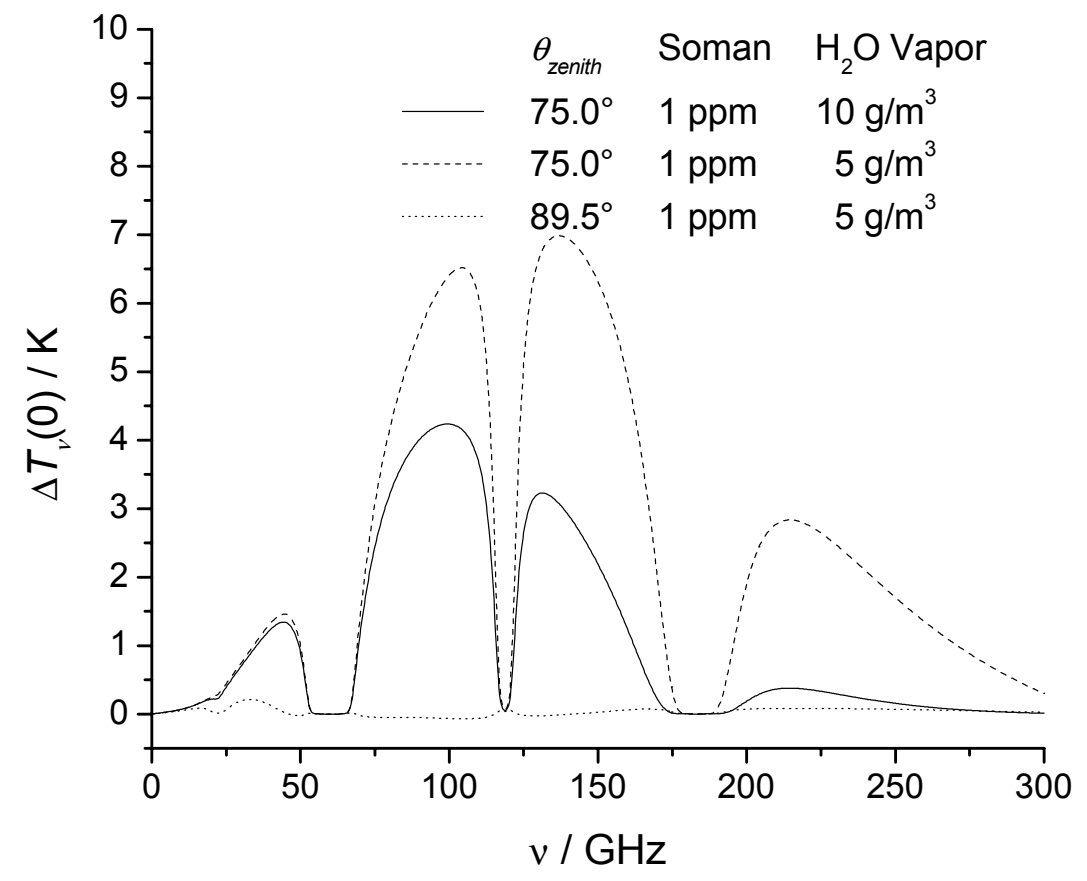

Figure 13. Plot of the differences in brightness temperatures with and without a cloud of $1 \mu \mathrm{mol} / \mathrm{mol}$ [1 ppm] soman in the optical path. The pathlength through the cloud is fixed at $1 \mathrm{~km}$. The cloud is assumed to reside between $1 \mathrm{~km}$ and $2 \mathrm{~km}$ in altitude. Model results are presented for zenith angles of $75^{\circ}$ and $89.5^{\circ}$ and for water-vapor concentrations of $5 \mathrm{~g} / \mathrm{m}^{3}$ and $10 \mathrm{~g} / \mathrm{m}^{3}$. 


\section{Minimum Detectable $\Delta T_{\downarrow}(0)$ from a Chemical-Agent Cloud under Realistic Conditions}

Information about the radiometer performance and about the stability of the thermal background being measured are required to assess the ability of a microwave or millimeterwave sensor to identify and quantify a chemical-agent release. The radiometer performance is stated in terms of the minimum detectable signal or MDS. MDS is calculated from the standard deviation of the radiometer noise [29]. Single-detectorelement radiometers operating near or below $100 \mathrm{GHz}$ can achieve an MDS of better than $0.05 \mathrm{~K}$ with integration times $<100 \mathrm{~ms}$ [30]. Imaging systems generally have higher MDS values. An inexpensive $94 \mathrm{GHz}$ imaging system has been demonstrated, consisting of a $10 \times 10$ focal-plane array detector with each array element having an MDS $<1 \mathrm{~K}$. The imaging system has a frame rate of $60 \mathrm{~Hz}$ [31]. For a recent review of millimeterwave imaging see Reference [32].

Fluctuations in the thermal background also affect overall system performance, particularly if they occur at a frequency which makes it difficult to discriminate background drift from a chemical-agent release. Typically, the chemical-agent sensor will continually view a region of space waiting for the occurrence of a change in the background brightness temperature in one or more monitoring channels indicative of a chemical agent cloud. Background thermal fluctuations with temporal, spatial, and spectral properties similar to that expected for a chemical agent cloud can potentially cause false alarms, requiring that the detection threshold be set high, with a concomitant reduction in sensitivity. Higher frequency fluctuations will appear as noise, also leading to a reduction in detection sensitivity.

Background thermal fluctuations arise from atmospheric turbulence and winds and local solar heating causing temperature, pressure, and humidity drifts. Other sources of background fluctuations include smoke, dust, and haze that commonly occur on the battlefield. In attempts to understand these atmospheric fluctuations several measurements have been made of the ground-level microwave and millimeterwave brightness temperature as a function of time. Salmon and Appleby [33], for example, examined the brightness temperature fluctuations in two bands, a Ka band from $26 \mathrm{GHz}$ to $40 \mathrm{GHz}$ and a W band from $90 \mathrm{GHz}$ to $98 \mathrm{GHz}$, under cloudy, light-rain conditions. They observed short-term temperature fluctuations of $10 \mathrm{mK}$ to $20 \mathrm{mK}$ in the $\mathrm{Ka}$ band and $20 \mathrm{mK}$ to $30 \mathrm{mK}$ in the $\mathrm{W}$ band at a frequency of $1 \mathrm{~Hz}$. At lower frequencies $(10 \mathrm{mHz})$, the temperature fluctuations were significantly greater, as much as $5 \mathrm{~K}$ for the $\mathrm{Ka}$ band and $10 \mathrm{~K}$ for the $\mathrm{W}$ band. These large temperature fluctuations were attributed to cloud movement.

Clear-sky measurements at $20.6 \mathrm{GHz}$ by Han et al. [34] over a period of 12 hours reveal changes in brightness temperature of nearly $7 \mathrm{~K}$ out of approximately $24 \mathrm{~K}$ over a period of 12 hours. These changes were well modeled by radiative transfer models using Raman lidar, radiosonde, and radio-acoustic sounding to provide input water-vapor and temperature profiles. Hogg et al. [35] performed measurements over a period of a week and observed changes in the water vapor column by a factor of four, from approximately 
$2 \mathrm{~cm}$ to $0.5 \mathrm{~cm}$. Smoot et al. [36] observed dramatic changes in brightness temperature, approximately $11 \mathrm{~K}$ over the period of $68 \mathrm{~min}$, during poor weather conditions. They note that changes in the magnitude of the water-vapor column amounts drive the changes in brightness temperatures [36]. Changes in atmospheric pressure can also affect the contribution of oxygen to the brightness temperature, but this effect is significantly smaller than changes in water vapor [37], primarily since factional changes in atmospheric pressure are significantly smaller than fractional changes in water-vapor column amounts. We note that at $90 \mathrm{GHz}$ the brightness temperature change with watervapor column change for a vertical-looking radiometer is approximately $29 \mathrm{~K} / \mathrm{cm} \mathrm{[36].}$ Figures 5 and 10 demonstrate that the ground-level brightness temperature is sensitive to the amount of water vapor along the optical path.

In summary, the minimum detectable $\Delta T_{\nu}(0)$ will generally be limited by fluctuations in the atmospheric brightness temperature. Integration of a companion sensor with the radiometer, such as a Raman lidar instrument, together with accurate real-time radiative transfer modeling may improve the situation.

\section{CONCLUSIONS}

The present modeling results demonstrate that the direct application of ground-based, upward-looking, microwave-to-millimeterwave radiometry will be challenged by the poor atmospheric opacity at near horizontal viewing angles of greatest interest for standoff detection of a chemical-agent release. The small changes in brightness temperature expected for realistic chemical-agent release scenarios will likely be masked by temporal changes in the background brightness temperature induced by atmospheric turbulence giving rise to fluctuations in the water-vapor column, the major contributor to the background radiance. Options to circumvent this problem include only operating the sensor in low-humidity weather conditions and providing sufficient spectral coverage of the microwave-to-millimeterwave band to obtain data to correct for water-vapor fluctuations. Alternatively, the radiometer could be used in tandem with other sensors, such as lidar, which can provide accurate water-vapor spectral and temporal profiles for correcting the microwave-to-millimeterwave measurements.

Many of these limiting issues are reduced or eliminated when the cloud being sensed has a temperature significantly above that of the background gas. Such a situation may arise following the explosive release of an agent or when an agent, precursor, or decomposition produced is suspected in a smoke-stack plume. Sensitivity will depend on the size of the hot column of gas and the time for the temperature to return to that of the ambient background air.

The present modeling has not addressed other potential applications of microwave-tomillimeterwave technology for the standoff detection of chemical agents. Such application could include active lidar or radar technology [38] and passive downwardlooking radiometers mounted on airplanes, unmanned aerial vehicles (UAVs), or satellites. Radar and lidar technologies will require high sensitivity due to the weak backscatter from chemical agent clouds at these long wavelengths. Downward sensing is 
likewise difficult due to the brightness temperature noise arising from ground clutter. Such noise has been found to be on the order of several kelvin, and is subject to significant variation [39]. The magnitude of this variation will depend on whether the surface has natural structures with typically high emissivities such as vegetation and water or man-made structures with emissivities varying from near zero to near unity such as concrete and metal. Future studies will examine more closely these potential applications of microwave and millimeterwave methods. 


\section{REFERENCES}

1. A table of Chemical Warfare Agent Characteristics is available form the U.S. Army Chemical School website at http://www.wood.army.mil/cmdoc/WFS/CWA/CW\%20agent\%20characteristics. PDF.

2. Joint Service Lightweight Standoff Chemical Agent Detector (JSLSCAD) brochure from General Dynamics (2004). Available at http://www.gdatp.com/products/detection/jslscad/JSLSCAD.pdf.

3. M. Abaie, "Artemis Advance Planning Briefing for Industry," DoD CB Defense Advance Planning Briefing for Industry, National Defense Industrial Association, April 8-9, 2003. (Available at http://proceedings.ndia.org/dod_cb/Wednesday_AM/Abaie.pdf)

4. J. Friend and C. Gelman, "Preliminary Study of the Microwave Spectrum of GB for Possible Application to Detection," Chemical Warfare Labs, Army Chemical Center, Md (1956). Available from STINET using Accession Number: AD00884802.

5. C. W. Gillies, M. B. Tabacco, T. G. DiGiuseppe, "Development of a Microwave Rotational Detector for Chemical Agent Warning and Detection," Geo-Centers, Inc., Newton Centre, MA (1986). Available from STINET using Accession Number: ADB108314.

6. A. R. H. Walker, R. D. Suenram, A. Samuels, J. Jensen, M. W. Ellzy, J. M. Lochner, D. Zeroka, "Rotational spectrum of Sarin," Journal Of Molecular Spectroscopy 207, 77-82 (2001).

7. R. D. Suenram, R. S. DaBell, A. R. H. Walker, R. J. Lavrich, D. F. Plusquellic. M. W. Ellzy, J. M. Lochner, L. Cash, J. O. Jensen, and A. C. Samuels, "Rotational spectra of the Diastereorners of Soman," Journal Of Molecular Spectroscopy, 224, 176-184 (2004).

8. S. D. Christesen, "Microwave Detection of Chemical Agents: A Review," Chemical Research Development and Engineering Center, Aberdeen Proving Ground, MD, (1986). Available from STINET using Accession Number: ADA171472.

9. M. McIlwain, D. Smith, and E. Finnegan, "Theoretical Evaluation of Microwave Absorption for Chemical Agent Detection," Geo-Centers, Inc., Newton Center, MA (1983). Available fro STINET using Accession Number ADB075312.

10. D. F. Flanigan, "The Spectral Signatures of Chemical Agent Vapors and Aerosols," Chemical Research and Development Center, Aberdeen Proving 
Grounds, MD (1985). Available from STINET using Accession Number:

ADB092373.

11. For a description of how to perform these simulations see, V. B. Podobedov, R. J. Lavrich, T. M. Korter, G. T. Fraser, D. F. Plusquellic, and A. C. Samuels, "Submillimeter and THz Detection of Dimethyl Methyl Phosphonate in Air," NIST Internal Report, NISTIR 7134 (2004).

12. R. D. Suenram, F. J. Lovas, D. F. Plusquellic, A. Lesarri, Y. Kawashima, J. O. Jensen, and A. C. Samuels, "Fourier Transform Microwave Spectrum and ab Initio Study of Dimethyl Methylphosphonate," Journal of Molecular Spectroscopy 211, 110-118 (2002).

13. H. M. Pickett, "The Fitting and Prediction of Vibration-Rotation Spectra with Spin Interactions,” Journal of Molecular Spectroscopy 148, 371-377 (1991). The program is available at http://spec.jpl.nasa.gov/.

14. S. W. Sharpe, T. J. Johnson, J. Kleimeyer and B. Rowland, The DPG/PNNL InfraRed Spectral Library, Pacific Northwest National Laboratory, Richland, WA 9932 and Dugway Proving Grounds, Dugway, UT 84022, Version 1.1 (2002).

15. S. W. Sharpe, T. J. Johnson, P. M. Chu, J. Kleimeyer and B. Rowland, "Quantitative, Infrared Spectra of Vapor Phase Chemical Agents," in Chemical and Biological Sensing IV. Edited by P.J. Gardner, Proceedings of the SPIE, 5085, 19-27 (2003).

16. S. W. Sharpe, R. L. Sams, T. J. Johnson, P. M. Chu, G. C. Rhoderick, C. George, F. R. Guenther, "Creation of $0.10-\mathrm{cm}^{-1}$ resolution quantitative infrared spectral libraries for gas samples," in Vibrational Spectroscopy-based Sensor Systems, edited by S. D. Christesen and A. J. Sedlacek, Proceedings of the SPIE, 4577,1224 (2002). The database is available at the following website: https://secure.pnl.gov/nsd/NSD.nsf/Welcome?OpenForm.

17. D. F. Flanigan, "Hazardous cloud imaging: a new way of using passive infrared," Applied Optics 36, 7027-7036 (1997).

18. D. F. Flanigan, "Prediction of the limits of detection of hazardous vapors by passive infrared with the use of MODTRAN," Applied Optics 35, 6090-6098 (1996).

19. D. F. Flanigan, "Detection of organic vapors with active and passive sensors: a comparison," Applied Optics 25, 4253-4260 (1986).

20. D. A. Ligon, A. E. Wetmore, and P. S. Gillespie, "Simulation of the passive infrared spectral signatures of bioaerosol and natural fog clouds immersed in the background atmosphere," Optics Express 10, 909-919 (2002). 
21. J. W. Waters, “Atmospheric Effects: Absorption and Emission by Atmospheric Gases," in Methods of Experimental Physics, Vol. 12 Astrophysics, Part B: Radio Telescopes, edited by M.L. Meeks, Academic Press, New York (1976), pp. 142176.

22. F. T. Ulaby, R. K. Moore, and A. K. Fung, Microwave Remote Sensing, Active and Passive, Volume I, Microwave Remote Sensing: Fundamentals and Radiometry, Addison-Wesley, Reading MA, (1981).

23. H.J. Liebe, "A contribution to modeling atmospheric millimeter-wave properties," FREQUENZ 41, 31-36 (1987).

24. H.J. Liebe, “An updated model for millimeter wave propagation in moist air," Radio Science 20, 1069-1089 (1985).

25. H.J. Liebe, "MPM - an atmospheric millimeter-wave propagation model," International Journal of Infrared and Millimeter Waves 10, 631-650 (1989).

26. R. K. Crane, "Atmospheric Effects: Refraction Effects in the Neutral Atmosphere," in Methods of Experimental Physics, Vol. 12 Astrophysics, Part B: Radio Telescopes, edited by M.L. Meeks, Academic Press, New York (1976), pp. 186-200.

27. L.S. Rothman, A. Barbe, D. Chris Benner, L.R. Brown, C. Camy-Peyret, M.R. Carleer, K. Chance, C. Clerbaux, V. Dana, V.M. Devi, A. Fayt,J.-M. Flaudi, R.R. Gamachej, A. Goldmank, D. Jacquemarta, K.W. Jucksa, W.J. Lafferty, J.-Y. Mandin, S.T. Massie, V. Nemtchinov, D.A. Newnham, A. Perrin, C.P. Rinsland, J. Schroeder, K.M. Smith, M.A.H. Smith, K. Tang,R.A. Toth, J. Vander Auwera, P. Varanasi, and K. Yoshino, Journal of Quantitative Spectroscopy \& Radiative Transfer 82 5-44 (2003).

28. N. E. Gaut and E. C. Reifenstein III, Environmental Research and Technology Report No. 13, Lexington, MA (1971).

29. R. M. Price, "Radiometers: Radiometer Fundamentals," in Methods of Experimental Physics, Vol. 12 Astrophysics, Part B: Radio Telescopes, edited by M.L. Meeks, Academic Press, New York (1976), pp. 201-224.

30. N. A. Salmon, "Passive Millimetre Wave Imaging and Absorption from Exhaust Gasses," Proceedings of the International University Conference, Electronics and Radiophysics of Ultra-High Frequencies, Saint Petersburg, May 1999, pp. 472474.

31. R. Augeri, J. Whelehan, J. Taub, and R. Rudish, "Low Cost Passive Millimeter Wave Imaging System," JJW Consulting, Inc. Smithtown, NY and AIL Systems, 
Inc. Deer Park, NY. (1998). Available from STINET using Accession Number: ADB280115.

32. L. Yujiri, M. Shoucri, and P. Moffa, "Passive Millimeter-Wave Imaging," IEEE Microwave Magazine 4, 39-50 (2003).

33. N. A. Salmon and R. Appleby, "Millimetre Wave Sky Radiation Temperature Fluctuations," Proceedings of the 25th International Conference on Infrared and Millimeter Waves, Beijing, China, Sept. 2000, pp. 463 - 464.

34. Y. Han, J. B. Snider, E. R. Westwater, S. H. Melfi, and R. A. Ferrare, "Observations of water vapor by ground-based microwave radiometers and Raman lidar,” Journal of Geophysical Research 99, 18695-18702 (1994).

35. G. F. Smoot, S. M. Levin, A. Kogut, G. De Amici, and C. Witebsky, "Atmospheric emission variation measurements at 3,0.9, and $0.33 \mathrm{~cm}$ wavelength,” Radio Science 22, 521-528 (1987).

36. D. C. Hogg, F. O. Guiraud, and W. B. Sweezy, “The Short-Term Temporal Spectrum of Precipitable Water Vapor," Science 213, 1112-1113 (1981).

37. M. Bersanelli, M. Bensadoun, L. Danese, G. Deamici, A. Kogut, S. Levin, M. Limon, D. Maino, G. F. Smoot, and C. Witebsky, "Measurements of The Atmospheric Emission and Variations in the 1-90 GHz Range," Planetary and Space Science 43, 1467-1472 (1995).

38. N. Gopalsami and A. C. Raptis, "Millimeter-Wave Radar Sensing of Airborne Chemicals," IEEE Transactions on Microwave Theory and Techniques," 49, 646653 (2001).

39. W. J. Wilson, R. J. Howard, A. C. Ibbott, G. S. Parks, and W. B. Ricketts, "Millimeter-Wave Imaging Sensor," IEEE Transactions on Microwave Theory and Techniques," 34, 1026-1035 (1986). 


\section{APPENDIX 1.}

Microwave Transition Frequencies for Molecular Oxygen $\left({ }^{16} \mathrm{O}_{2}\right)$ from Waters [21]

\begin{tabular}{lll}
\hline$N$ & $\nu_{N-} / \mathrm{GHz}$ & $v_{\mathrm{N}^{+}} / \mathrm{GHz}$ \\
\hline 1 & 118.750343 & 56.264766 \\
3 & 62.486255 & 58,446580 \\
5 & 60.306044 & 59.590978 \\
7 & 59.164215 & 60.434776 \\
9 & 58.323885 & 61.150570 \\
11 & 57.612488 & 61.800169 \\
13 & 56.968180 & 62.411223 \\
15 & 56.363393 & 62.997991 \\
17 & 55.783819 & 63.568520 \\
19 & 55.221372 & 64.127777 \\
21 & 54.671145 & 64.678914 \\
23 & 54.1302 & 65.22412 \\
25 & 53.5959 & 65.764744 \\
27 & 53.0669 & 66.30206 \\
29 & 52.5424 & 66.83677 \\
31 & 52.0214 & 67.36951 \\
33 & 51.50302 & 67.90073 \\
35 & 50.9873 & 68.4308 \\
37 & 50.4736 & 68.9601 \\
39 & 49.9618 & 69.4887 \\
\hline
\end{tabular}




\section{APPENDIX 2}

Spectroscopic parameters for rotational transitions of $\mathrm{H}_{2}{ }^{16} \mathrm{O}$ contributing to the atmospheric opacity between 0 and $300 \mathrm{GHz}$ from Waters [21]

\begin{tabular}{|c|c|c|c|c|c|c|c|c|}
\hline Transition & $\begin{array}{c}\text { Frequency } \\
(\mathrm{GHz})\end{array}$ & $g_{l}$ & $\left|\phi_{l m}\right|^{2}$ & $\begin{array}{c}E_{m} \\
\left(\mathrm{~cm}^{-1}\right)\end{array}$ & $\begin{array}{c}E_{l} \\
\left(\mathrm{~cm}^{-1}\right)\end{array}$ & $\begin{array}{c}\Delta v_{l m}{ }^{0} \\
(\mathrm{GHz})\end{array}$ & $\begin{array}{c}\Delta v_{l m}\left(\mathrm{H}_{2} \mathrm{O}\right) \\
(\mathrm{GHz})\end{array}$ & $x$ \\
\hline $6_{16}-5_{23}$ & 22.23515 & 3 & 0.0549 & 447.30 & 446.56 & 2.85 & 13.68 & 0.626 \\
\hline $3_{13}-2_{20}$ & 183.31012 & 1 & 0.1015 & 142.27 & 136.16 & 2.68 & 14.49 & 0.649 \\
\hline $10_{29}-9_{36}$ & 323. & 3 & 0.0870 & 1293.80 & 1283.02 & 2.30 & 12.04 & 0.420 \\
\hline $5_{15}-4_{22}$ & 32.1538 & 1 & 0.0891 & 326.62 & 315.78 & 3.03 & 15.21 & 0.619 \\
\hline $4_{14}-3_{21}$ & 380.1968 & 3 & 0.1224 & 224.84 & 212.16 & 3.19 & 15.84 & 0.630 \\
\hline $10_{37}-11_{210}$ & 390. & 1 & 0.0680 & 1538.31 & 1525.31 & 2.11 & 11.42 & 0.330 \\
\hline $7_{53}-6_{60}$ & 436. & 1 & 0.0820 & 1059.63 & 1045.03 & 1.50 & 7.94 & 0.290 \\
\hline $6_{43}-5_{50}$ & 438. & 3 & 0.0987 & 756.76 & 742.11 & 1.94 & 10.44 & 0.360 \\
\hline $7_{52}-6_{61}$ & 442. & 3 & 0.0820 & 1059.90 & 1045.11 & 1.51 & 8.13 & 0.332 \\
\hline $4_{23}-3_{30}$ & 448.0008 & 3 & 0.1316 & 300.37 & 285.42 & 2.47 & 14.24 & 0.510 \\
\hline
\end{tabular}

